\title{
Microstructural Evolution of SA508 Grade 3 Steel during Hot Deformation
}

\author{
Paranjayee Mandal (D), Himanshu Lalvani, Andrew Barrow, and Jack Adams
}

\author{
(Submitted July 22, 2019; in revised form January 21, 2020; published online February 4, 2020)
}

\begin{abstract}
SA508 grade 3 steel is widely used in the manufacture of large-scale forged components for nuclear reactor applications. Numerical models have already been established to simulate industrial forging process of grade 3 steel; however, limited information is available on the microstructural evolution of this steel during hot forging operation. This work focuses on the flow behavior and related microstructural evolution in grade 3 steel with detailed analysis on the interfacial friction, texture and hardness evolution. Uniaxial hot compression tests were conducted over a range of test temperatures $\left(880-1130{ }^{\circ} \mathrm{C}\right)$ and true strain rates $(0.001-1 / s)$, representative of the industrial hot forging conditions. Two different deformation mechanisms, MDRX at the lowest forging temperature and DRV along with DRX at the highest forging temperature, were observed showing marked impact on the final microstructure and hardness. A random fiber-type weak deformation texture was observed irrespective of the test temperatures and strain rates used. The microstructural changes from the as-received to the various deformed conditions were quantified. The quantitative data are the key to obtain accurate parameters for DRV and DRX processes that affect the accuracy of the mathematical models.
\end{abstract}

Keywords crystallographic texture, hardness, hot deformation, mechanical properties, microstructural evolution, SA508 grade 3 steel

\section{Introduction}

ASME SA508 is a widely used steel grade in nuclear reactor pressure vessels (RPV), steam generators (SG) and pressurizers. Among the SA508 steel variants, the grade 3 steel is a more preferable choice over other grades (grade 1 and grade 2) due to its improved strength, excellent toughness, high weldability and superior resistance to irradiation embrittlement. Bowen et al. (Ref 1) reported that the large rod-shaped and spherical cementites formed at grain/lath boundary reduced the toughness and increased the ductile-brittle transition temperature (DBTT) of the heat-treated SA508 grade 3 steel. Im et al. (Ref 2) showed that the nano-sized needle-shaped $\mathrm{M}_{2} \mathrm{C}$ carbides significantly improved the yield and tensile strength of this material and simultaneously lowered the DBTT, thereby increased the cleavage fracture stress. The needle-shaped $\mathrm{M}_{2} \mathrm{C}$ carbides, densely formed within the ferritic matrix, attracted interest due to their significantly higher resistance to irradiation embrittlement and improved strength. Pous-Romero et al. (Ref 3) summarized the influence of multi-step heattreatments on this steel grade in achieving optimum austenite grain size and modeled the austenite grain growth in RPVs. The

Paranjayee Mandal and Himanshu Lalvani, Advanced Forming Research Centre, University of Strathclyde, 85 Inchinnan Drive, Inchinnan, Renfrewshire PA4 9LJ, UK; and Andrew Barrow and Jack Adams, Rolls-Royce plc, SW1-70, Raynesway, PO Box 2000, Derby DE21 7XX, UK. Contact e-mails: paranjayee.mandal@strath.ac.uk,_himanshu.lalvani@strath.ac.uk, andrew.barrow2@rolls-royce.com, and Jack.Adams@rolls-royce.com.

optimum grain size is important in order to achieve desired mechanical properties and therefore longer service life of grade 3 steel. These studies were primarily focused on establishing a basic understanding of the structural, mechanical and service behavior of this steel grade. The outcomes from these studies were used to modify the microstructure for meeting the demanding requirements of hostile service environment involving high temperature, high pressure and exposure to highenergy neutrons. On the other hand, limited studies have been conducted on the hot deformation behavior of the SA508 grade 3 steel focussing mainly on the effects of process parameters and prediction of the material behavior during hot forging by establishing different numerical models. Sun et al. (Ref 4) reviewed the previous studies on SA508 grade 3 steel and identified lack of information about the mechanical response at different temperatures, strains and strain rates in plastic deformation region, which was important for designing heavy forging processes of large components. They modeled mechanical behavior of this steel during hot deformation (in the range of $700-1200{ }^{\circ} \mathrm{C}$ with strain rates of $0.001-10 / \mathrm{s}$ ) by incorporating the work hardening (WH), dynamic recovery (DRV) and dynamic recrystallization (DRX) using Bergstrom dislocationbased model and Avrami-type equation. As the temperature reached just above Ac3 (temperature at which transformation from ferrite to austenite occurs), they measured the prior austenite grain size (PAGS) by quenching the sample and then using an empirical formula, they calculated the initial PAGS before hot deformation. This PAGS value is an important input parameter for calculating both DRX and DRV parameters and final mixed grain size of the forged product. The effectiveness of this mathematical model depends on the accuracy of these parameters. Although Sun et al. (Ref 4) did not provide any insights into the microstructural evolution, but they proved the effectiveness of their FEM model for a nuclear conical shell forging process. Sui et al. (Ref 5) carried out similar type of simulation work focused on inhomogeneous hot deformation (IHD) process of SA508 grade 3 steel. They used average grain 
size calculated from optical micrographs as an input to the FEM model, but did not provide details on the microstructural evolution. The model showed that the temperature had more influence over the DRX than the strain and strain rates involved during IHD. Typically, the forging of large components involves multi-passes, where the material is often subjected to dynamic recovery (DRV), dynamic recrystallization (DRX), static recrystallization (SRX) and metadynamic recrystallization (MDRX) leading to subsequent changes in the microstructural and mechanical characteristics. As the strain in the first pass exceeds the critical strain of DRX, the MDRX takes place by continuous growth of the nuclei formed by DRX during deformation at high temperature. The MDRX significantly reduces stress in the subsequent passes and therefore refines the grain size during hot forging process. Recently, Dong et al. (Ref 6) investigated the MDRX behavior of SA508 grade 3 steel during isothermal double-hit hot compression tests performed at a wide range of forming temperatures $\left(950-1250{ }^{\circ} \mathrm{C}\right)$, strain rates $(0.001-0.1 / \mathrm{s})$ and inter-stage delay times. They observed significant effects of temperature and strain rate on MDRX behavior of grade 3 steel as compared to the effects of both prestrain and initial austenite grain size. Based on the experimental results obtained, they also established the kinetic equations and the grain size model for predicting the softening fractions during MDRX. They used it as an input in the commercial FE software for modeling and optimizing the hot forging process of grade 3 steel. In summary, these studies simulated the hot forging operation of grade 3 steel within a wide range of temperature $\left(700-1250{ }^{\circ} \mathrm{C}\right)$ and strain rate $(0.005-10 / \mathrm{s})$ values with a maximum strain of 0.8 and predicted the flow stress under different deformation mechanisms with the help of different mathematical models. The accuracy of these models depends on the value of DRX and DRV parameters; thus, focus was mainly on calculation of the Zener-Holloman parameter $Z$ and measurement of PAGS before forging. Beside this, no detailed microstructural analysis before or after the compression tests representing hot forging process was reported.

The originality of the current work is in providing a thorough insight on how the microstructure of SA508 grade 3 steel evolves during the hot forging process from the perspective of deformation mechanisms affecting the PAGS, the effective grain size, orientation of effective grains, crystallographic texture and hardness. To replicate the industrial large open die forging operation of SA508 grade 3 steel components, isothermal uniaxial compression tests were carried out over a specific range of test temperatures $\left(880-1130{ }^{\circ} \mathrm{C}\right)$ and true strain rates $(0.001-1 / \mathrm{s})$ with a true strain of unity. The standard strain rates in any open die forging process are typically in the range of $1-500 / \mathrm{s}(\operatorname{Ref} 7)$; however, it is particularly in the range of $0.001-10 / \mathrm{s}$ for various steels (including the one utilized in the current study) used in the nuclear plant RPVs (Ref 4, 8, 9). There is a continuous drive to improve the existing numerical models for predicting accurate strains and microstructure evolution during hot forging processes. The success of any FE process model for hot forging processes relies on the accuracy of flow stress data obtained from the isothermal and constant strain rate compression tests carried out at relevant parameters. Producing the corrected flow stress data at those relevant parameters and quantification of the grain size at those respective deformation conditions are two important inputs to the FE process models in order to obtain accurate predictions for desired microstructure in the end product. This study addresses both, and the related microstructural analysis helps to understand the softening mechanisms occurring at different parametric combinations. Moreover, quantification of this microstructural data is a key in obtaining precise DRX and DRV parameters that influence the accuracy of the FE process models.

\section{Experimental Details}

Table 1 shows the elemental composition of the SA508 grade 3 steel blocks (12 blocks, each having a dimension of $63 \mathrm{~mm}$ length $\times 19 \mathrm{~mm}$ width $\times 15 \mathrm{~mm}$ height) as supplied by Rolls Royce Plc. Figure 1(a) shows the orientation of machined cylindrical compression test samples (12 mm diameter $\times 18 \mathrm{~mm}$ height) from these blocks, and Fig. 1(b) shows the sample co-ordinate system consisting of compression direction (CD) and radial direction (RD) as used in this study. Before the compression tests, the machined samples were coated with glass lubricant (Prince Grey Glass Lubricant 87.2.237) in order to avoid any oxidation and sticking issues with the platens of the testing machine at high temperature. Zwick Z250 and HA250 mechanical test machines were used for conducting isothermal hot compression tests at atmospheric condition in the temperature range of $880-1130{ }^{\circ} \mathrm{C}$ and the true strain rate range of $0.001-1 / \mathrm{s}$ with a true strain of unity. Figure 2 shows the schematic diagram of the hot deformation process, and Table 2 details the compression test matrix. The samples were soaked at the required deformation temperatures for $30 \mathrm{~min}$ to achieve a uniform temperature distribution, and it was maintained within $\pm 3{ }^{\circ} \mathrm{C}$ throughout the duration of the test. The compression tests were performed as per the National Physical Laboratory (NPL) good practice guide, which details the experimental practice and measurement of the flow stress during isothermal uniaxial axisymmetric compression tests (Ref 10). The strain measurements were deduced from the displacement of the machine crosshead and adjusted to take account of the machine compliance. The measured flow curves were then corrected for both the interfacial friction and the adiabatic heating. The values of barreling and ovality coefficients calculated from the deformed samples were within the acceptable limits as per the NPL good practice guide, and thus, the validity of each compression test was ensured (Ref 10). After compression, the deformed samples were quenched within 3$5 \mathrm{~s}$ from end of the tests to freeze the respective deformed microstructure.

The samples were then sectioned and mounted in conductive resin molds. The mounted samples were ground with $\mathrm{SiC}$ abrasive grit papers and finish-polished using UltraPol $9 \mu \mathrm{m}$, Trident $3 \mu \mathrm{m}$, MasterTex $1 \mu \mathrm{m}$ and Microcloth with $0.02 \mu \mathrm{m}$ colloidal silica suspension. Then, the samples were etched using nital (solution of $2 \% \mathrm{HNO} 3$ in ethanol) for PAGS

Table 1 Elemental composition of as-received SA508 grade 3 machined steel blocks

\begin{tabular}{lccccc}
\hline Element & $\mathbf{C}$ & $\mathbf{M n}$ & $\mathbf{N i}$ & $\mathbf{C r}$ & Mo \\
\hline $\mathrm{Wt} \%$ & 0.206 & 1.280 & 0.644 & 0.140 & 0.493 \\
\hline Element & $\mathbf{S i}$ & & $\mathbf{S}$ & $\mathbf{P}$ & $\mathbf{F e}$ \\
\hline $\mathrm{Wt} \%$ & 0.321 & 0.014 & 0.002 & 97.093 \\
\hline
\end{tabular}


(a)

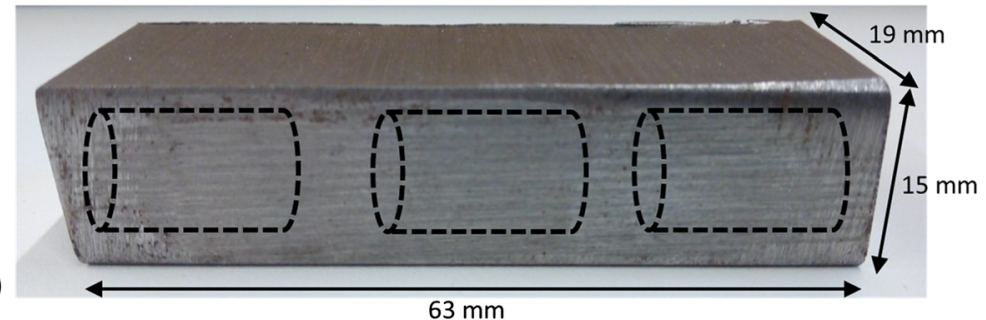

(b)
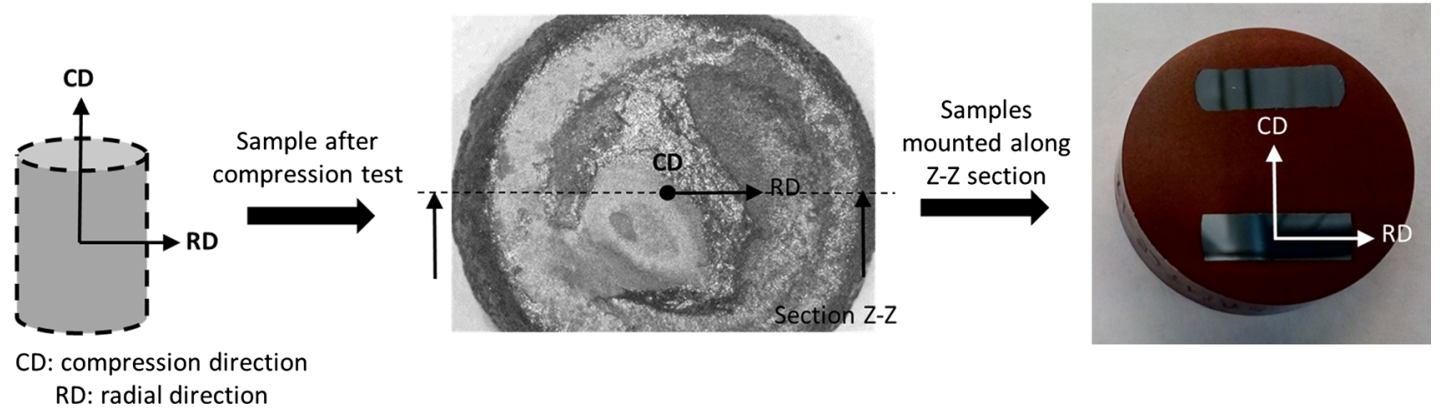

Fig. 1 (a) Orientation of cylindrical samples machined from the as-received steel blocks and (b) Sample co-ordinate system used in this work (images not to scale)

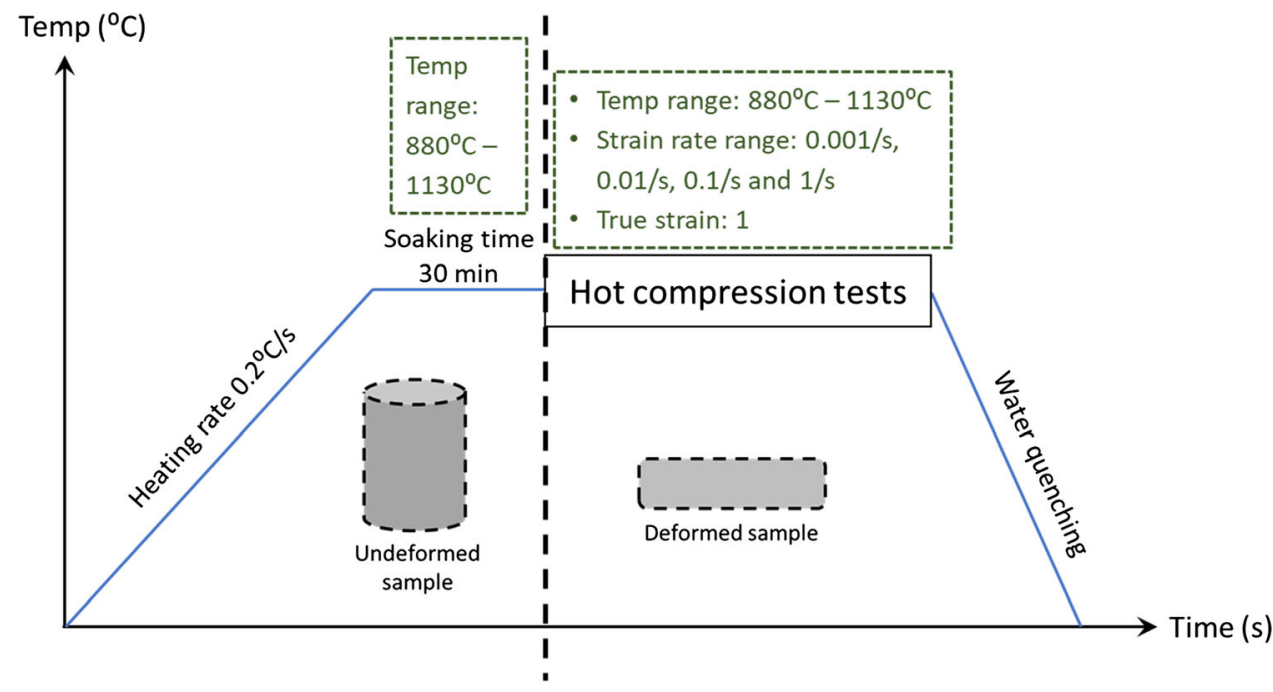

Fig. 2 Schematic diagram of the hot deformation process for SA508 grade 3 steel

measurement. A Leica DM1200M optical microscope was used to capture the micrographs and conduct related grain size analysis using the Leica LAS-X image analysis software coupled with the microscope. Figure 3 shows an example of PAGS analysis using the image analysis software where the automatic grain detection technique is used to identify the prior austenite grains (PAGs) in the as-received sample. The software detects the different PAGs with different colors and provides a grain size distribution. The quantitative grain size analysis carried out in this study is as per the ASTM standard E112 (Ref 11). The as-received sample and the four deformed samples covering the maximum and minimum parametric range of the compression test matrix, i.e., $880{ }^{\circ} \mathrm{C}-0.001 / \mathrm{s}$, $880{ }^{\circ} \mathrm{C}-1 / \mathrm{s}, 1130{ }^{\circ} \mathrm{C}-0.001 / \mathrm{s}$ and $1130{ }^{\circ} \mathrm{C}-1 / \mathrm{s}$, were further vibro-polished for EBSD analysis. A FEI Quanta FEG 250 SEM was used to collect the EBSD data, from the longitudinal section, along the sample axis at a distance of $h / 3$ from one end of the sample, where $h$ was the deformed sample height. Evans and Scharning (Ref 12) reported that the portion of deformed specimen at $h / 3$ distance from each end of the cylindrical sample was representative of the bulk strain experienced during hot axisymmetric compression tests under constant strain rate. Hence, it is very important to capture microstructure from this region for quantitative analysis to avoid areas within the deformed specimens that have inhomogeneous strain distribution, i.e., dead zones. The orientation mapping was performed using a rectangular grid with a step size of $0.4 \mu \mathrm{m}$ and $0.3 \mu \mathrm{m}$, respectively, for as-received and deformed samples with an indexing rate of $98-99 \%$. Both the bainitic and martensitic packets, i.e., effective grains, were identified by the high-angle grain boundaries (HAGB) with a misorientation angle of $\theta>15^{\circ}$, and the minimum size of accepted effective grains 
Table 2 Test matrix for hot compression tests of SA508 grade 3 steel samples

\begin{tabular}{lcccc}
\hline Temperature $\left({ }^{\circ} \mathrm{C}\right)$ & & $\begin{array}{c}\text { Zwick Z250 (for low strain rates) } \\
\text { True strain rates (per second) }\end{array}$ & Zwick HA250 (for high strain rate) \\
\hline 880 & 0.001 & 0.01 & 0.1 & 1 \\
963 & 0.001 & 0.01 & 0.1 & 1 \\
1046 & 0.001 & 0.01 & 0.1 & 1 \\
1130 & 0.001 & 0.01 & 0.1 & 1 \\
\hline
\end{tabular}

(a) as-received microstructure

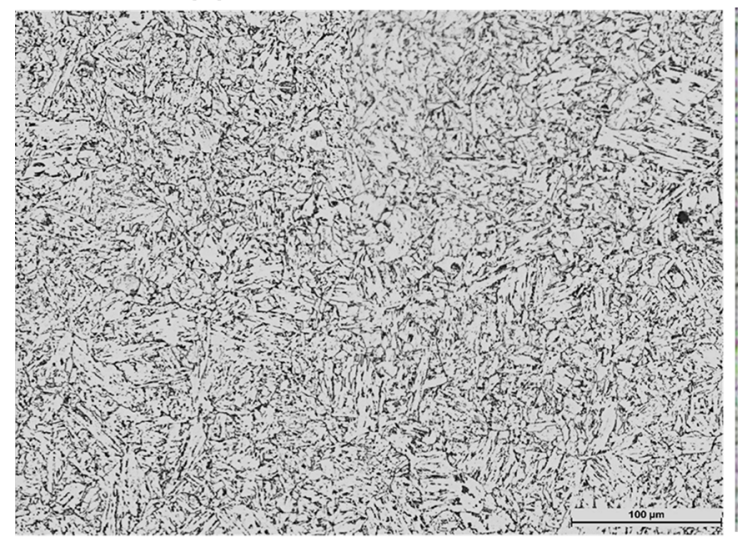

(b) PAGs identified using software

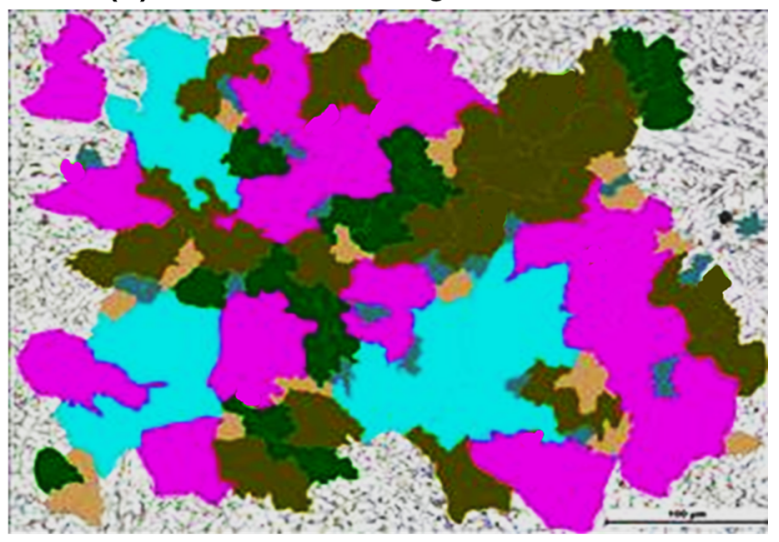

(c) PAGS distribution for as-received sample

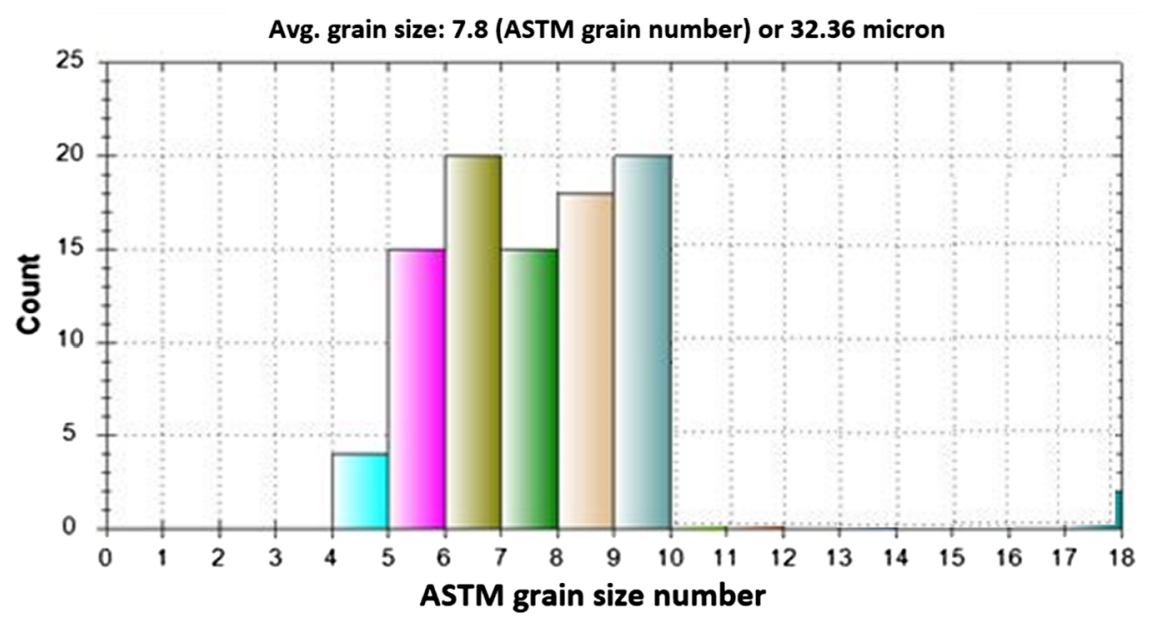

Fig. 3 Representative example of PAGS analysis using Leica LAS-X software-(a) as-received microstructure, (b) PAGS identified using software (different colors indicate different grain sizes) and (c) PAGS distribution in as-received sample

was taken as 5 pixels in this study (Ref 13). The EBSD data processing was carried out using HKL Channel-5 postprocessing software. A Struers hardness tester was used to measure the average hardness of these five samples according to ASTM standard E384-11 (Ref 14). The indents (>100 indents) were made in a rectangular matrix using a Vickers indenter with a fixed load of $5 \mathrm{kgf}$, and the distance between any two indents was kept as $1 \mathrm{~mm}$ along both $X$ and $Y$ directions ensuring more than 3 diagonal widths spacing between any two indents as recommended for the steel samples (Ref 15).

\section{Evolution of Mechanical Properties during Hot Deformation}

\subsection{Analysis of Flow Behavior}

Figure 4 summarizes the flow curves of SA508 grade 3 steel samples at different true strain rates $(0.001-1 / \mathrm{s})$ with a variation in the test temperature $\left(880-1130{ }^{\circ} \mathrm{C}\right)$. These flow stress curves have been corrected for frictional and adiabatic heating losses as outlined in slab analysis method (Ref 16) using an in-house 

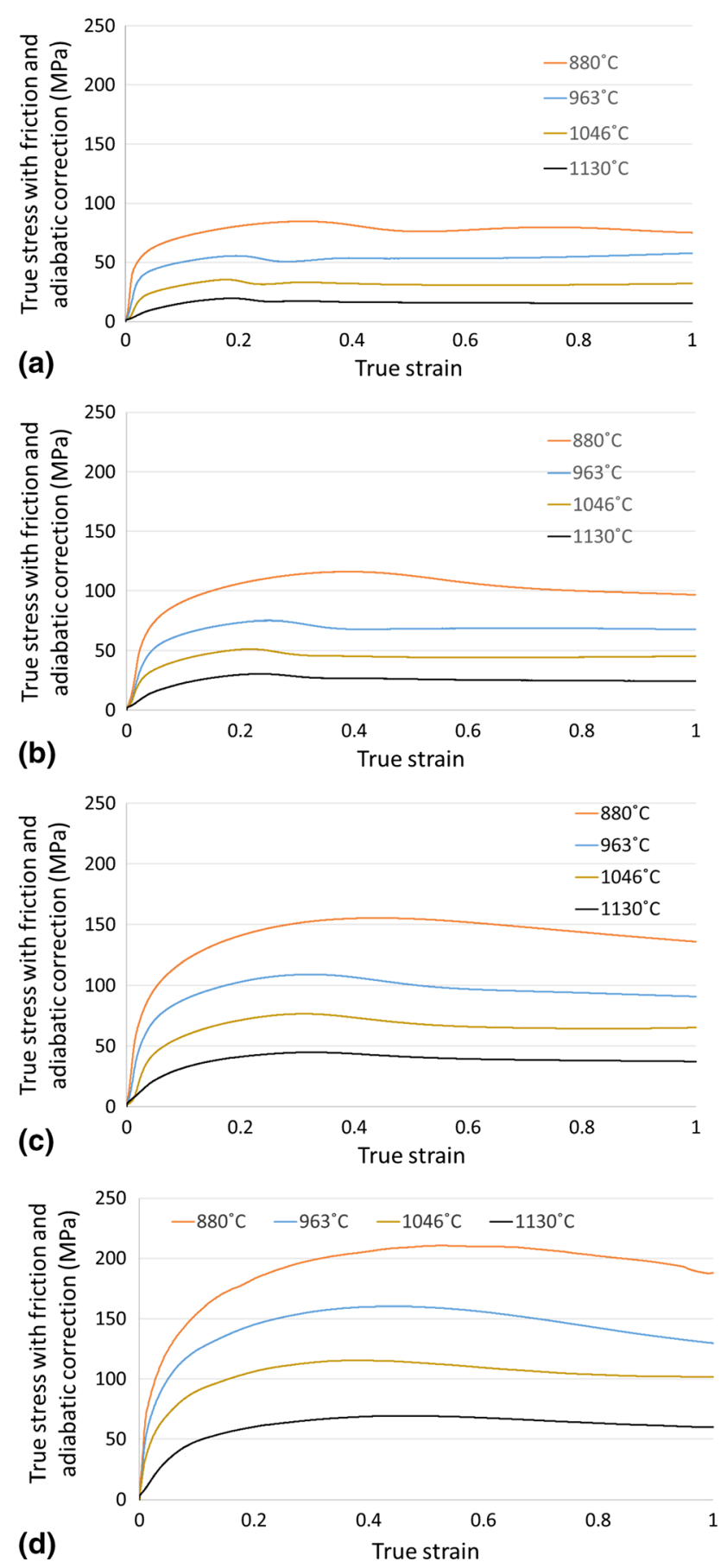

Fig. 4 Flow curves of SA508 grade 3 steel at different test temperatures $\left(880-1130{ }^{\circ} \mathrm{C}\right.$ ) and at true strain rates of (a) $0.001 / \mathrm{s}$, (b) $0.01 / \mathrm{s}$, (c) $0.1 / \mathrm{s}$ and (d) $1 / \mathrm{s}$, respectively

developed Matlab code. Figure 5 shows combined flow stress curves before and after implementing the necessary corrections for one of the test samples, i.e., $1130{ }^{\circ} \mathrm{C}-1 / \mathrm{s}$. The blue line, named as 'true stress without friction correction,' shows the true stress curve as a direct output of the compression test, i.e., raw flow stress data, without taking into account any influence of interfacial friction and adiabatic heating during the test. The red line, named as 'true stress with friction correction,' shows the flow stress curve considering corrected for interfacial friction loss. The green line, named as 'true stress with friction and adiabatic heating correction,' shows the corrected flow stress curve considering both frictional and adiabatic heating losses. Equation 1 and Equation 2 summarizes the steps for correcting those losses according to the slab analysis method. In this method, the energy under the flow stress curve is calculated subtracting the conduction heat losses from the ends and then the remainder is converted to a temperature rise. A linear temperature sensitivity is assumed during the temperature correction to this flow curve, and the value is obtained from the flow stress data. These corrections on the flow stress data are performed by an in-house developed Mathcad code, and Table 3 lists the input data used in that Mathcad code. Wan et al. (Ref 17) have described and performed similar analysis during hot deformation of a nickel-based U720LI alloy.

The corrected (for both frictional and adiabatic heating losses) flow stress curves in Fig. 4 show a typical stress-strain behavior influenced by both work hardening and thermally activated softening mechanisms. DRV and DRX are two important softening mechanisms that significantly influence the flow stress behavior during high-temperature deformation of metals. Typically, DRX is dominant in face-centered cubic (FCC) materials owing to their low stacking fault energy (SFE), whereas DRV has been found dominant in body-centered cubic (BCC) materials due to their high SFE. However, under certain combination of deformation temperature and true strain rate values during hot deformation, the flow behavior of $\mathrm{BCC}$ materials is influenced by either the presence of both DRX and DRV or a change in softening mechanism from DRX to DRV. For example, Zhang et al. (Ref 18) showed the presence of both DRX and DRV during hot deformation behavior of BCC Ti-153 metastable beta titanium alloy. The DRX was dominant at a particular combination of deformation temperature and strain rate, i.e., $1050{ }^{\circ} \mathrm{C}-0.01 / \mathrm{s}$, and $\mathrm{DRV}$ was dominant under either lower or higher temperature and strain rate combinations $\left(850{ }^{\circ} \mathrm{C}-0.01 / \mathrm{s}\right.$ and $1100{ }^{\circ} \mathrm{C}-1 / \mathrm{s}$, respectively). DRX results in grain refinement and annihilation of deformation defects, thereby significantly improving the mechanical properties and hence has advantages over DRV. On the other hand, Davenport et al. (Ref 19) mentioned a change in flow softening mechanism from, DRX to DRV, for BCC plain C-Mn steel (max. 0.25\% C and $1.6 \% \mathrm{Mn})$. The DRX was dominant at higher temperature and lower strain rate combination $\left(1100{ }^{\circ} \mathrm{C}-1 / \mathrm{s}\right)$, whereas the softening mechanism completely changed from DRX to DRV at lower temperature and significantly higher strain rate combinations $\left(900{ }^{\circ} \mathrm{C}-10 / \mathrm{s}\right.$ and $1000{ }^{\circ} \mathrm{C}-50 / \mathrm{s}$, respectively). These variations are typically characterized using Zener-Holloman parameter $Z$, where low $Z$ value indicates occurrence of rapid DRX and high $Z$ value shows the presence of either DRV or a combination of both $\mathrm{WH}$ and DRV in the BCC materials. The flow instability is observed at very high $Z$ values, which varies depending on the material. In the current study, Fig. 4 shows a linear increase in peak stress values with decrease in deformation temperature (at any fixed strain rate) and with increase in strain rate (at any fixed temperature). Particularly, a significant decrease in the flow stress value is observed when the deformation temperature is $1046{ }^{\circ} \mathrm{C}$ and above. Feng et al. (Ref 20) reported similar behavior during high-temperature deformation of a high-nitrogen martensitic 30Cr15MolN stainless steel. They reported that the low strain rate provided enough time for energy accumulation, whereas the high deformation temperature promoted dissolution of precipitates, dislocation movements and grain boundary migration for nucleation and growth of DRX grains eventually leading to a decrease in the flow stress level. Beside this, another 


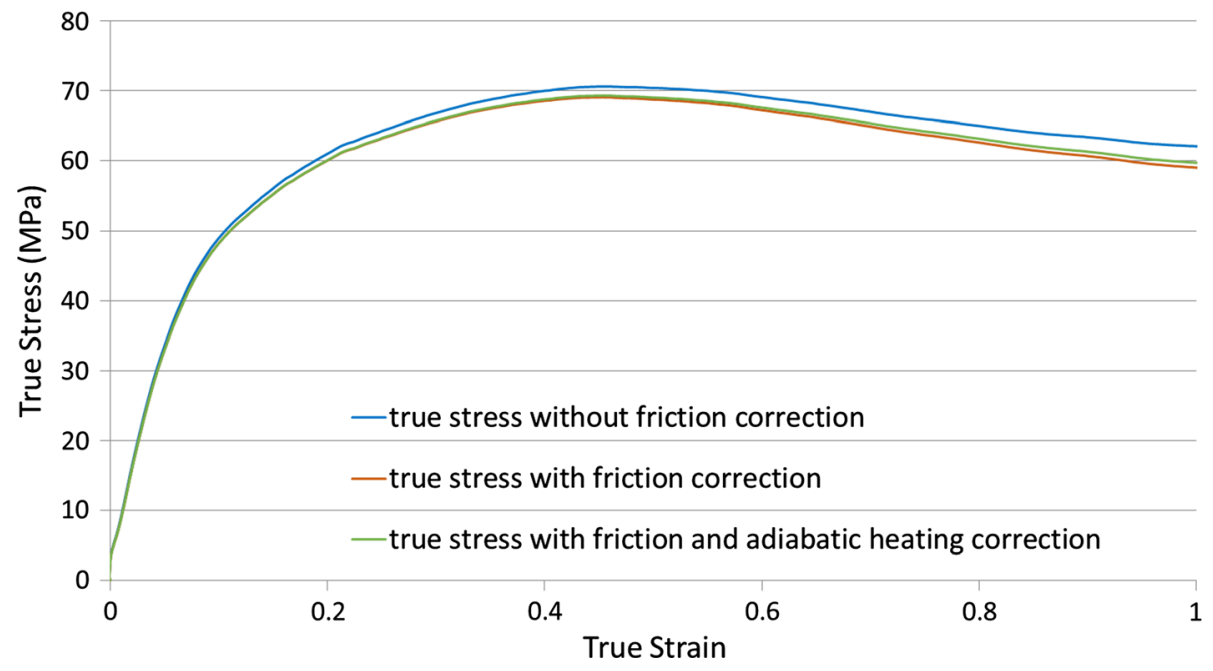

Fig. 5 Example showing the flow stress curves for a representative sample $\left(1130{ }^{\circ} \mathrm{C}-1 / \mathrm{s}\right)$ before and after implementing the necessary corrections

Table 3 List of input data used in the Mathcad code for correction of flow curves

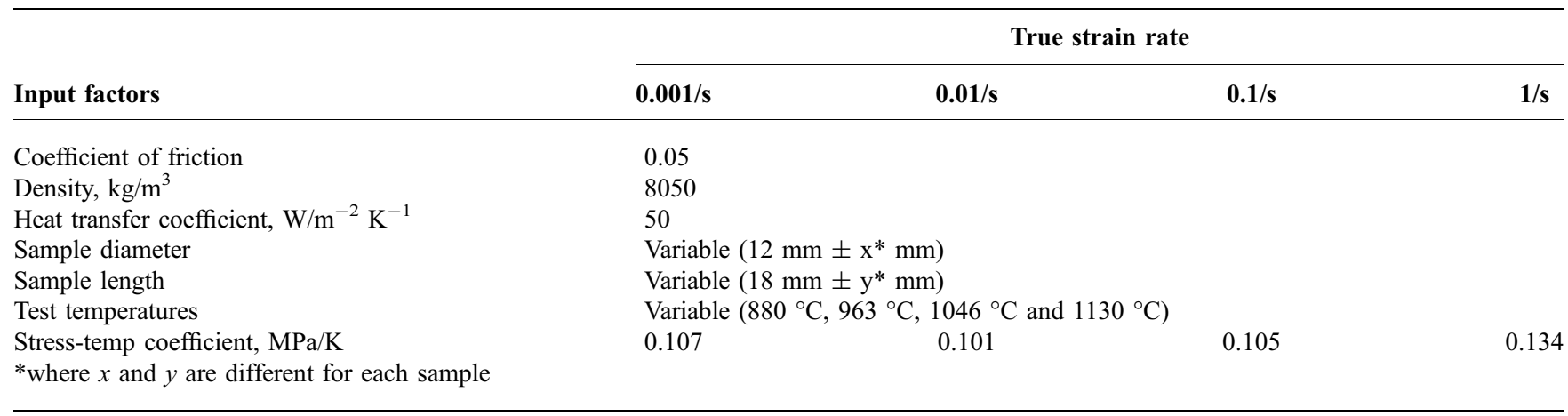

notable fact in the current study is the presence of hump in the flow stress curves for all three low strain rate tests $(0.1-0.001 / \mathrm{s})$ irrespective of the deformation temperatures. The initial rise of the flow stress is attributed to the WH due to increase in dislocation density. With increase in the strain value, the effect of WH is balanced by both DRV and DRX, which leads to formation of a hump in the flow curves. A steady-state condition is achieved when the balance is reached to an equilibrium state. Specifically, for $1 / \mathrm{s}$ strain rate tests, the hump becomes wider and the steady-state condition is achieved faster as compared to other low strain rate tests. Thus, $880{ }^{\circ} \mathrm{C}-1 / \mathrm{s}$ and the $1130{ }^{\circ} \mathrm{C}-0.001 / \mathrm{s}$ test conditions exhibit maximum and minimum effect of $\mathrm{WH}$, respectively, along with significant effect of flow softening for the later. This is also evident from Fig. 6 showing relationship between WH rate $(\theta)$ and true stress as derived from the experimental data. Similar observations were also reported by Sun et al. (Ref 4). After the steady-state condition, all the flow curves in Fig. 4 show a downward trend irrespective of the strain rates and deformation temperatures used. This is attributed to the occurrence of DRX followed by DRV. Feng et al. (Ref 20) showed that the flow stress curves having a single peak followed by a steady-state condition typically indicated the appearance of DRX during hot deformation. The waviness observed at the end of the flow curves was attributed to DRV due to high migration of dislocations and with further deformation, and the dislocation density continued to increase leading to a second peak in the flow stress curve. Besides this, Fig. 7 shows the strain rate sensitivity $(m)$ of the deformed samples at different test temperatures. The highest and lowest peak stresses were observed for $880{ }^{\circ} \mathrm{C}-1 / \mathrm{s}$ and $1130{ }^{\circ} \mathrm{C}-0.001 / \mathrm{s}$ test conditions, respectively. The $m$ value was observed as $0.131,0.148,0.167$ and 0.182 for test temperatures $880{ }^{\circ} \mathrm{C}, 963{ }^{\circ} \mathrm{C}, 1046{ }^{\circ} \mathrm{C}$ and $1130{ }^{\circ} \mathrm{C}$, respectively. This slight difference in the $m$ values indicates the stability of the forging process, if performed within the specified parametric range as observed from the corrected stress-strain curves in Fig. 4.

\section{Equation 1: Correction of flow stress for frictional loss}

(a) Defining the effect of deformation on sample:

$$
\text { Shape }_{t}=\mu \cdot \frac{\sqrt{\frac{r^{2} \cdot h}{h \cdot e^{-\varepsilon_{t}}}}}{h \cdot e^{-\varepsilon_{t}}}
$$

(b) Corrected flow stress after frictional loss:

$$
\sigma_{-} \text {fric }_{t}=\frac{2 \sigma_{t}}{\left(\frac{1}{\text { Shape }_{t}}\right)^{2} \cdot\left(e^{2 \text { Shape }_{t}}-2 \cdot \text { Shape }_{t}-1\right)}
$$




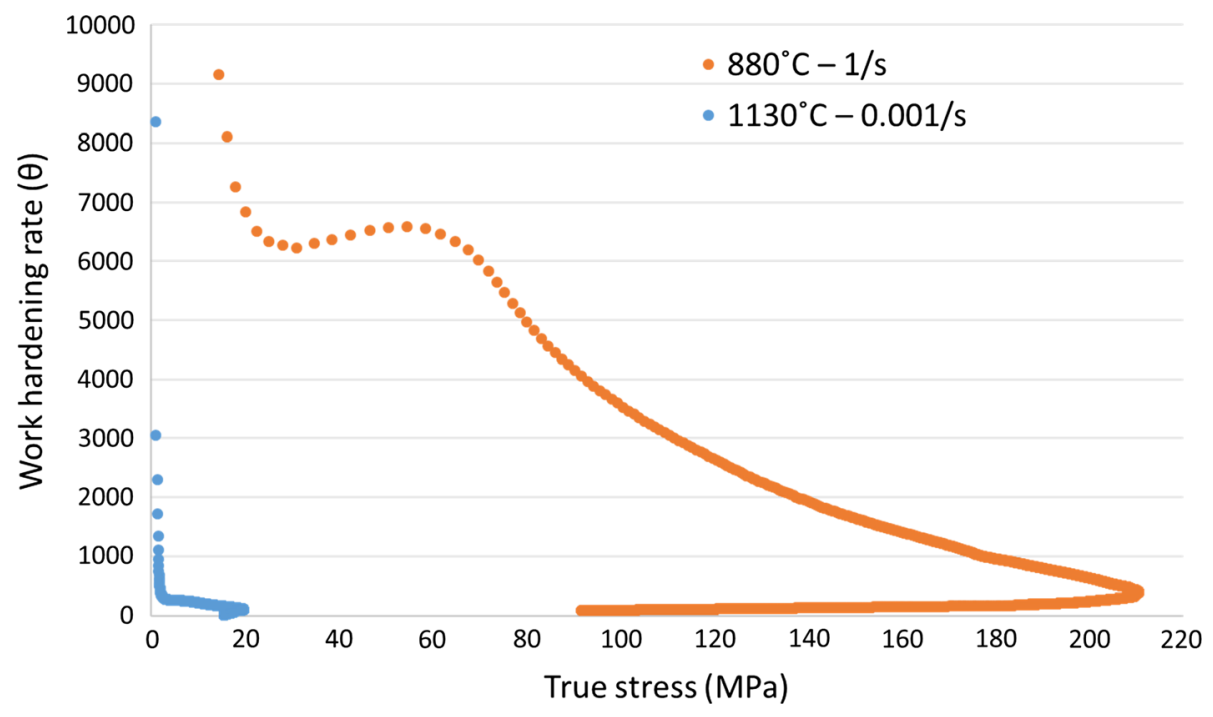

Fig. 6 Relationship between work hardening rate $(\theta)$ and true stress at two selected test conditions as derived from the experimental data

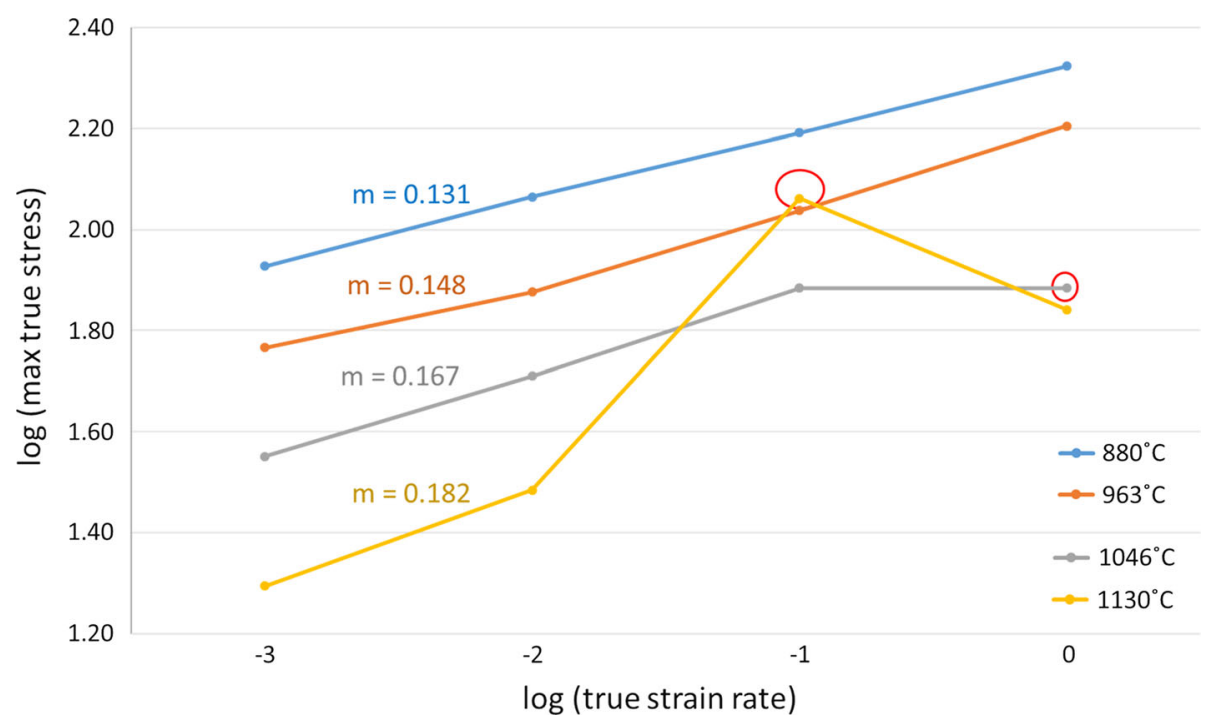

Fig. 7 Strain rate sensitivity $(\mathrm{m})$ at different test temperatures $\left(880-1130{ }^{\circ} \mathrm{C}\right)$ (outliers marked by red circles are not considered during analysis)

where, $\mu=$ friction coefficient of the hot deformation process, $r$ and $h=$ initial radius and height of the compressed test sample, respectively, and $\varepsilon=$ measured strain.

Equation 2: Correction of flow stress for loss due to adiabatic heating

(a) Defining the adiabatic temperature rise:

$$
\Delta T=\frac{\sum_{i=0}^{n-1}\left(\pi r^{2} \cdot h \cdot \sigma_{f r i c_{t}} \cdot 10^{6} \cdot\left(\varepsilon_{t}-\varepsilon_{t-1}\right)\right)}{C_{p} \cdot \rho \cdot \pi r^{2} \cdot h}
$$

where $\Delta T=$ maximum temperature rise assuming no heat loss, $C_{p}=$ specific heat of the material, $\rho=$ density of the material and $n=$ data length

(b) Defining the thermal losses due to conduction:

$$
\operatorname{loss}_{n+1}=d q_{n} \cdot 2 \pi r^{2} h \cdot \Delta T_{n}=\left(h \cdot \frac{\varepsilon_{t}-\varepsilon_{t-1}}{\dot{\varepsilon}}\right) \cdot 2 \pi r^{2} h \cdot \Delta T_{n}
$$

where $d q_{n}=$ heat flow per increment, $2 \pi r^{2} h=$ die contact area and $\dot{\varepsilon}=$ required strain rate

(c) Defining the corrected test temperature:

$$
\text { testtemp }_{t}=T+\Delta T_{t}
$$

Corrected flow stress after incorporating temperature rise and energy loss:

$$
\sigma_{-} \text {adia }_{t}=\sigma_{-} \text {fric }_{t}+\text { temp }_{\text {coeff }} \cdot\left(\text { testtemp }_{t}-\text { testtemp }_{1}\right)
$$

where $\mu=$ friction coefficient of the hot deformation process, $r$ and $h=$ initial radius and height of the compressed test sample, respectively, and $\varepsilon=$ measured strain. 


\subsection{Analysis of Interfacial Friction}

Interfacial friction is a key factor that influences the hot deformation behavior of all the metallic materials. Li et al. (Ref 21) determined the average Tresca friction coefficient $(\mu)$ of a high-temperature barrel compression test by measuring the degree of barreling as shown in Equation 3 using upper-bound theory. This friction coefficient was dependant on the surface quality of the material, deformation temperature as well as strain values; thus, it covered the entire range of friction that could be observed during hot deformation processes starting from the perfect sliding $(\mu=0)$ to the sticking friction $(\mu=1)$. The same approach has been used in this study, and Fig. 8 shows the variation in friction coefficient at different true strain rates $(0.001-1 / \mathrm{s})$ and test temperatures $\left(880-1130{ }^{\circ} \mathrm{C}\right)$. Mostly high sticking friction $(\mu=0.78-1.04)$ is observed for all true strain rates within the temperature range of $880-1046{ }^{\circ} \mathrm{C}$, whereas a minor reduction in friction coefficient $(\mu=0.63$ $0.75)$ is observed at $1130{ }^{\circ} \mathrm{C}$ irrespective of the strain rates used.

This reduction in friction could be attributed to the formation of thick oxide scale containing lubricious and low shear strength iron oxides, such as $\mathrm{FeO}$ and $\mathrm{Fe}_{3} \mathrm{O}_{4}$, at high temperature (Ref 22). In the current work, formation of such oxide layers is clearly evident from the SEM images and the related EDX analysis confirms the chemical composition as shown in Fig. 9. For example, both $1130{ }^{\circ} \mathrm{C}-0.001 / \mathrm{s}$ and $1130{ }^{\circ} \mathrm{C}-1 / \mathrm{s}$ samples show formation of thick oxide scales (400-760 $\mu \mathrm{m}$ ) with porosity and large cracks (Fig. 9a and b, respectively). The sharp peaks of both iron and oxygen are clearly observed from the EDX spectra when collected from the interlayers (i.e., the thin layer between steel sample and oxide layer) and the oxide layers at the top.

Equation 3: coefficient of friction calculation using upperbound theory

$$
\mu=((r / h) * b) /(4 / \sqrt{ } 3-2 b /(3 \sqrt{ } 3))
$$

where $\mu=$ friction coefficient of the hot deformation process, $r, h=$ average radius and height of the compressed test sample, respectively, and $b=$ barreling coefficient.

\section{Evolution of Microstructural Properties dur- ing Hot Deformation}

\subsection{Microstructure Analysis}

Figure 10 shows the microstructures of as-received material and undeformed samples soaked at different test temperatures (880-1130 ${ }^{\circ} \mathrm{C}$ ) for $30 \mathrm{~min}$ followed by water quenching. The as-received sample shows characteristic lower bainitic microstructure, i.e., thin plates of ferrite containing very fine laths of cementite, which is transformed into austenite at elevated temperatures. At the end of the soaking period, the austenitic microstructure is transformed into fine acicular martensitic lath structure due to water quenching. The quenched undeformed samples, soaked at $880{ }^{\circ} \mathrm{C}$ and $963{ }^{\circ} \mathrm{C}$, contain a microstructure exhibiting thicker martensitic laths, whereas samples soaked at $1046{ }^{\circ} \mathrm{C}$ or higher show the presence of finer martensitic laths. Furthermore, the as-received microstructure contains coarse carbide particles which dissolve completely when heated at those high temperatures.

Figure 11 shows microstructure of the compressed test samples deformed at the highest strain rate of $1 / \mathrm{s}$. The martensitic laths observed in this case are finer in the samples deformed at $1046{ }^{\circ} \mathrm{C}$ and $1130{ }^{\circ} \mathrm{C}$ when compared to others. Similarly, Fig. 12 shows the microstructure of the compressed test samples deformed at the lowest strain rate of $0.001 / \mathrm{s}$. In this case, martensitic laths appear coarser as compared to the 1/ $\mathrm{s}$ strain rate cases due to longer exposures at the test temperatures. It should be noted here that the contrast of these optical images might lead to the confusion in reader's mind that the prior austenite grain boundaries (PAGB) are not clearly distinguishable from the lath boundaries; however, this is not the case. The PAGBs were identified using the LAS-X software at a significantly high magnification in order to perform the measurement of PAGS as already demonstrated in Fig. 3.

Figure 13 summarizes the PAGS analysis for as-received material and all water-quenched undeformed and deformed samples. The as-received material has an average PAGS of $\sim 32 \mu \mathrm{m}$, which shows no significant changes when soaked up to $963{ }^{\circ} \mathrm{C}$ before deformation. The undeformed samples show a drastic rise in the average PAGS, i.e., $\sim 70 \mu \mathrm{m}$

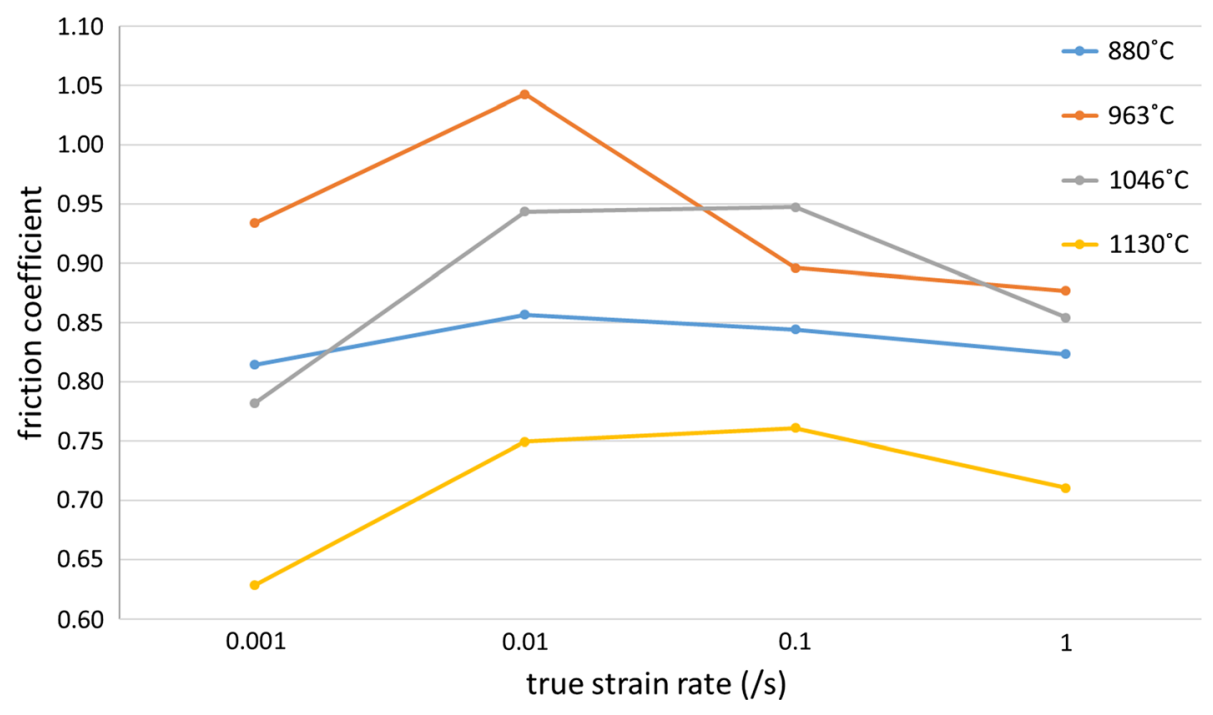

Fig. 8 Variation in friction coefficient at different true strain rates $(0.001-1 / \mathrm{s})$ and test temperatures $\left(880-1130{ }^{\circ} \mathrm{C}\right)$ 
(a)

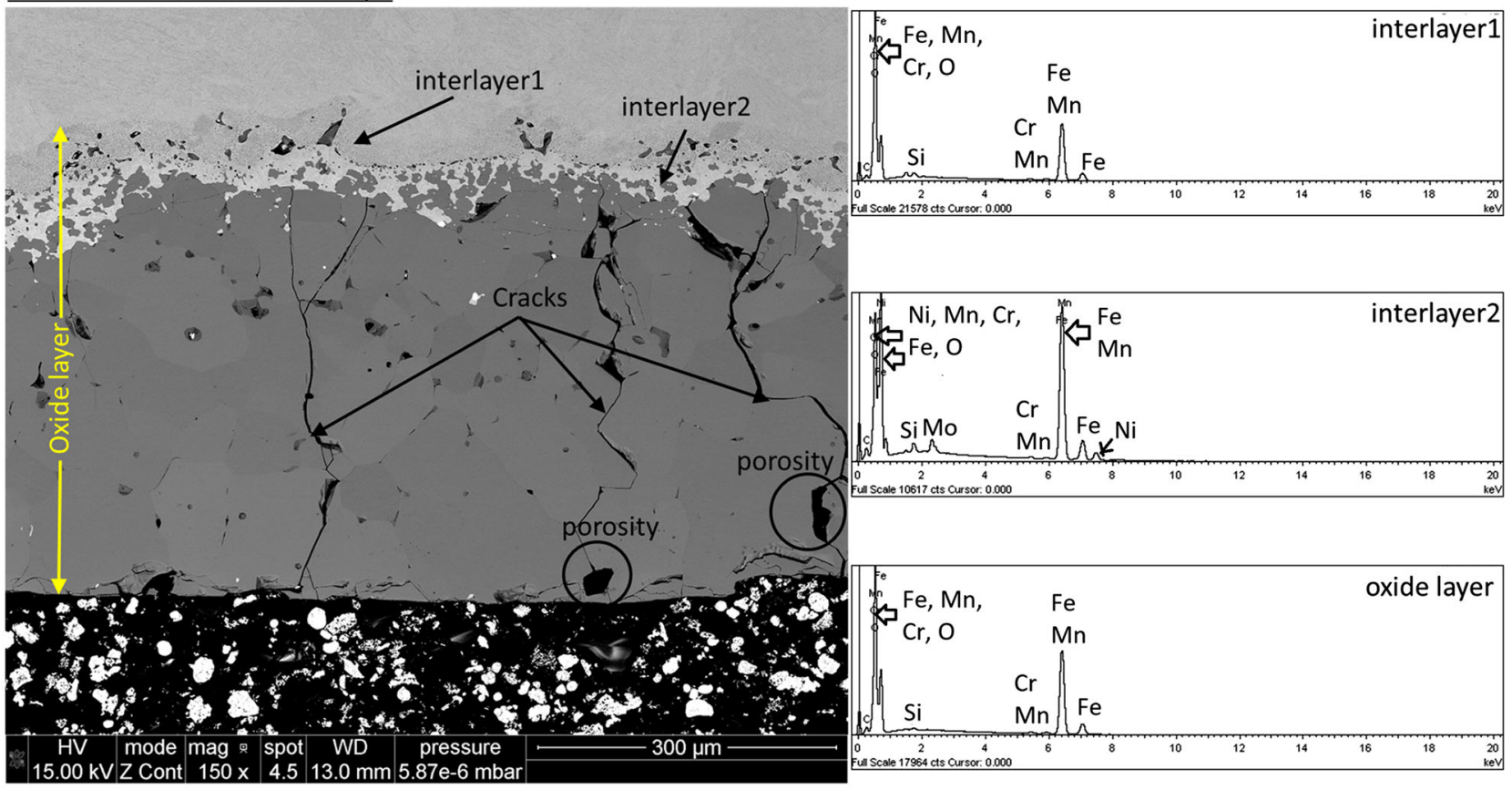

Test condition: $1130^{\circ} \mathrm{C}-1 / \mathrm{s}$

(b)
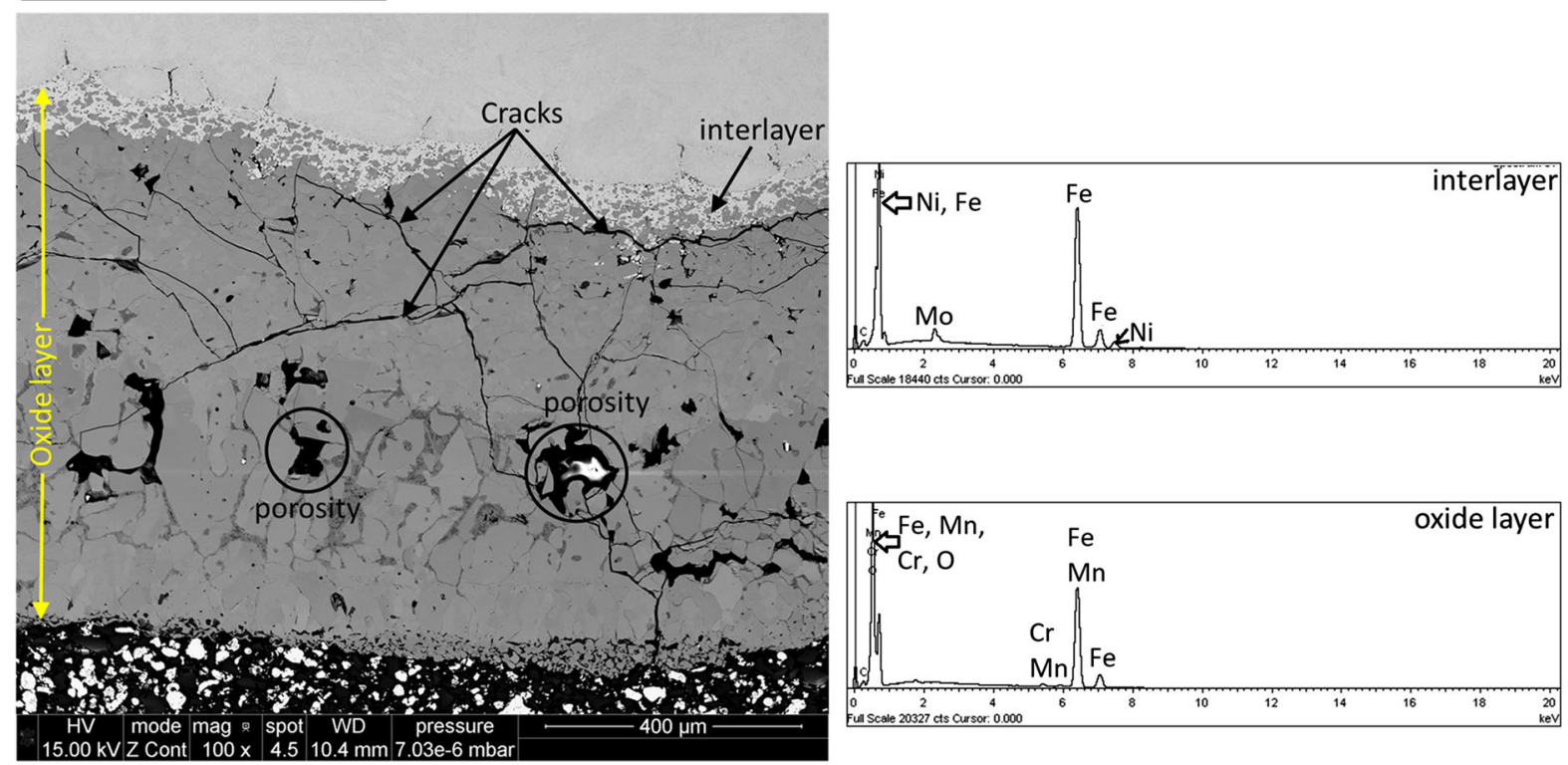

Fig. 9 SEM images showing the formation of lubricious oxide layer and respective EDX analysis from selected samples-(a) $1130{ }^{\circ} \mathrm{C}-0.001 / \mathrm{s}$ and (b) $1130{ }^{\circ} \mathrm{C}-1 / \mathrm{s}$

and $\sim 240 \mu \mathrm{m}$, when soaked at $1046{ }^{\circ} \mathrm{C}$ and $1130{ }^{\circ} \mathrm{C}$, respectively. In brief, almost no grain growth is observed in the undeformed samples up to $963{ }^{\circ} \mathrm{C}$, over which a rapid grain growth takes place. Slightly different behavior is observed for the deformed samples. The samples deformed up to $1046{ }^{\circ} \mathrm{C}$ show an average PAGS of $\sim 49$ to $60 \mu \mathrm{m}$ indicating insignificant grain growth irrespective of the different strain rates. When deformation temperature is increased to $1130{ }^{\circ} \mathrm{C}$, a drastic difference is observed in the average PAGS of samples deformed at two different strain rates. The sample deformed at $1 / \mathrm{s}$ shows minor increase in average PAGS, i.e., $\sim 70 \mu \mathrm{m}$, whereas the sample deformed at $0.001 / \mathrm{s}$ shows a rapid increase in average PAGS, i.e., $\sim 150 \mu \mathrm{m}$. This significant grain growth observed particularly in the undeformed $1130{ }^{\circ} \mathrm{C}$ sample and deformed $1130{ }^{\circ} \mathrm{C}-0.001 / \mathrm{s}$ sample could be attributed to three different phenomena-(1) reduction in Zener drag at that high temperature, (2) accumulation of enough energy for such grain growth at a very low strain rate and (3) the absence of carbide particles at the high temperature, which in turn accelerates the austenitic grain growth. Pous-Romero et al. (Ref 3) reported similar behavior for SA508 grade 3 steel under a series of different austenitization heat-treatments. They observed an insignificant austenite grain growth up to $965^{\circ} \mathrm{C}$ for $30 \mathrm{~min}$ soaking time. With increase in soaking time as well as the test temperature, a rapid austenite grain growth was observed over $\sim 940{ }^{\circ} \mathrm{C}$ due to reduction in Zener drag. Besides this, 


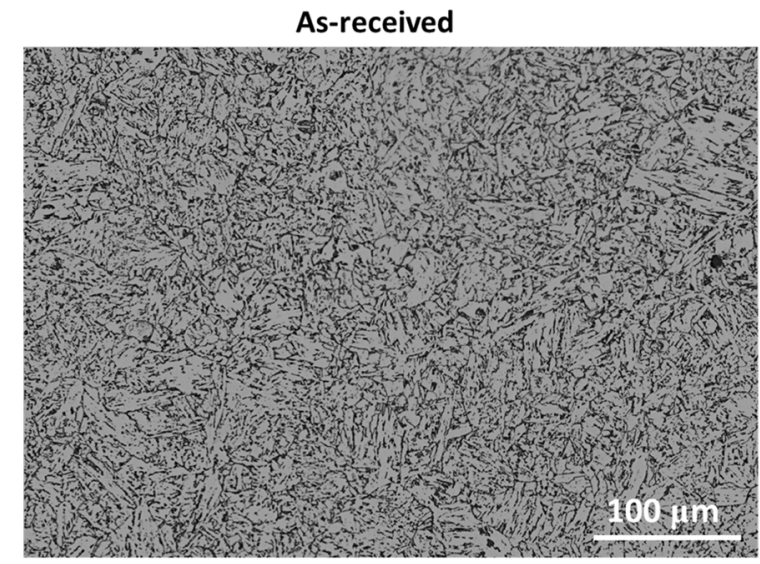

$880^{\circ} \mathrm{C}$

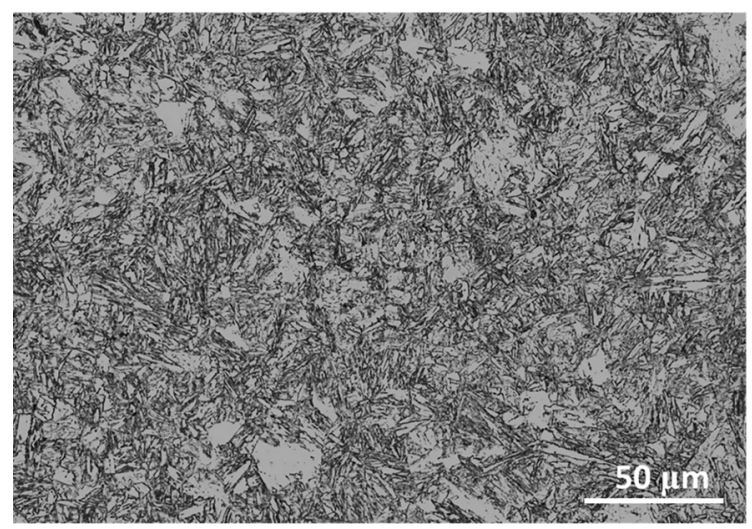

$1046^{\circ} \mathrm{C}$

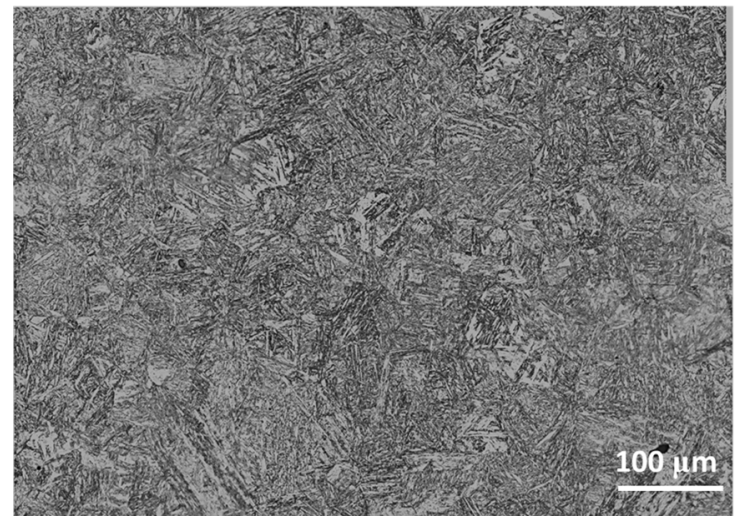

$963^{\circ} \mathrm{C}$

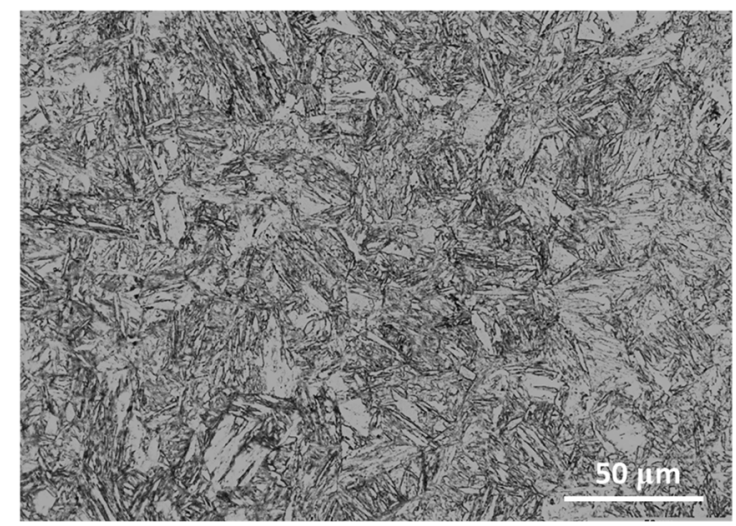

$1130^{\circ} \mathrm{C}$

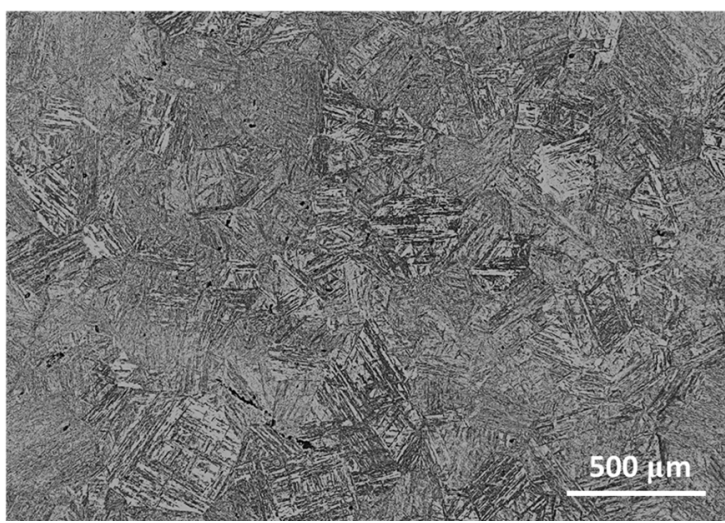

Fig. 10 Optical images showing the microstructure of as-received material and undeformed samples soaked for 30 min at different deformation temperatures $\left(880-1130{ }^{\circ} \mathrm{C}\right)$ before compression test

Papaefthymiou et al. (Ref 23) reported that the presence of undissolved carbides in a medium-carbon steel prevented the austenite grain growth at $950{ }^{\circ} \mathrm{C}$ resulting in a fine-grained microstructure. In this study, the specific temperature over which the rapid austenitic grain growth occurred is at $963{ }^{\circ} \mathrm{C}$ in case of undeformed sample and at $1046{ }^{\circ} \mathrm{C}$ for the deformed sample.

The as-received material and four deformed samples, i.e., $880{ }^{\circ} \mathrm{C}-0.001 / \mathrm{s}, 880{ }^{\circ} \mathrm{C}-1 / \mathrm{s}, 1130{ }^{\circ} \mathrm{C}-0.001 / \mathrm{s}$ and $1130{ }^{\circ} \mathrm{C}-1 / \mathrm{s}$, were further subjected to EBSD analysis for better understanding of the microstructure and texture evolution during hot deformation of the SA508 grade 3 steel. The strength and toughness of the martensitic steels are strongly dependent on the packet size, and hence, the packets are considered as 'effective grains' in a typical lath martensitic microstructure (Ref 24, 25). The bainitic microstructure shows similar microstructural features, but the difference lies in their mechanical properties. Morphologies are identified visually or using EBSD analysis where the thickness of the lath martensite is found to be finer than that of the bainite (Ref 26). Figure 14 shows the band contrast (BC) images and phase maps of the asreceived and the deformed samples. The green dots in $\mathrm{BC}$ images indicate the areas of no indexing. The as-received sample exhibits bainitic microstructure with larger effective grains, whereas deformed samples contain martensitic structure with significantly smaller effective grains as a result of water quenching. The phase maps show the BCC and FCC phases in yellow and blue colors, respectively, clearly demonstrating the 


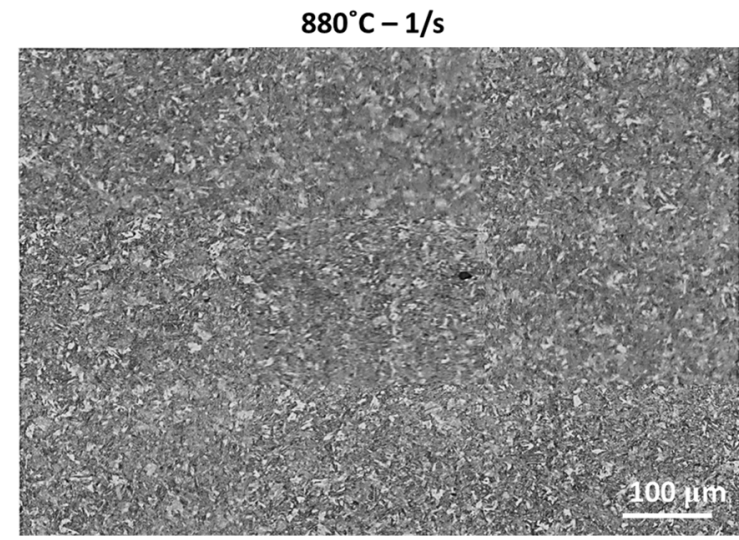

$1046^{\circ} \mathrm{C}-1 / \mathrm{s}$

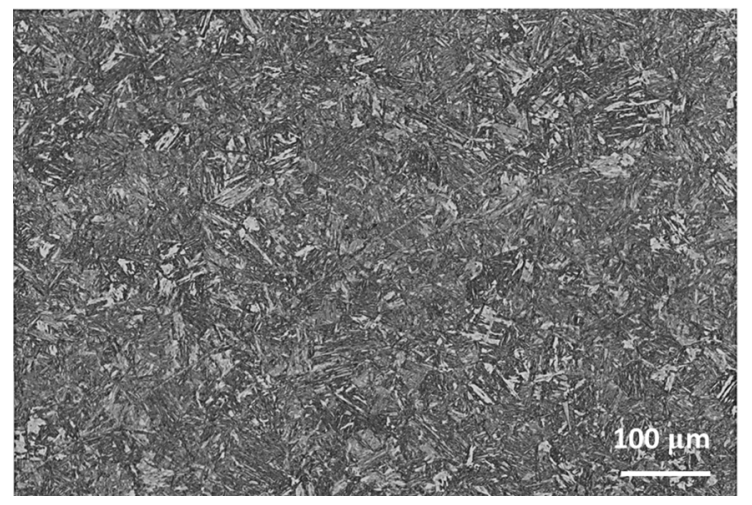

$963^{\circ} \mathrm{C}-1 / \mathrm{s}$

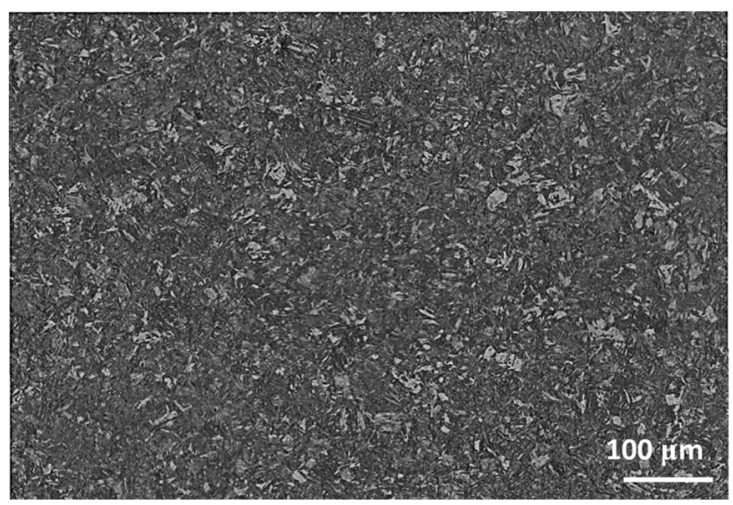

$1130^{\circ} \mathrm{C}-1 / \mathrm{s}$

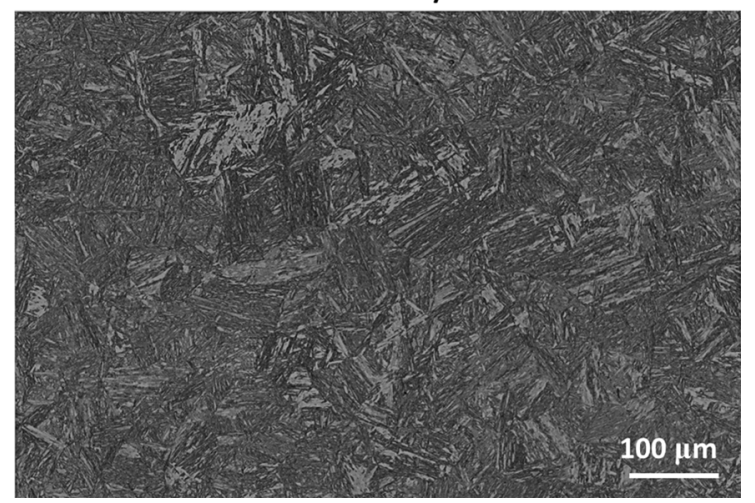

Fig. 11 Optical images showing the microstructure of samples deformed at true strain rate of $1 / \mathrm{s}$ and at different test temperatures (880$\left.1130{ }^{\circ} \mathrm{C}\right)$

difference between sizes and shapes of the bainitic and martensitic effective grains. The effective grain size is found to be smaller in the samples deformed at $880{ }^{\circ} \mathrm{C}$ and slightly larger for the samples deformed at $1130{ }^{\circ} \mathrm{C}$. Depending on the concentration of carbon, either $\mathrm{BCC}$ or $\mathrm{BCT}$ martensitic microstructure is formed in the quenched steel samples. At carbon concentration typically $<0.6 \mathrm{wt} . \%$, the microstructure is mostly $\mathrm{BCC}$ (c/a ratio is 1$)$, whereas it changes to BCT (c/a ratio $>1$ ) with further increase in carbon concentration (0.61.75 wt.\%) (Ref 27). Brust et al. (Ref 28) pointed out that the EBSD technique was inadequate in accurately measuring the lattice dimension of $c$ axis in high-carbon steels, and therefore, the BCT martensitic microstructure was often indexed as BCC martensitic microstructure due to pseudo-symmetry between BCT and BCC phases. The SA508 grade 3 steel used in this study is a low-carbon steel with only $\sim 0.2 \mathrm{wt} . \%$ carbon, which upon water quenching forms BCC martensitic microstructure. Thus, yellow color indicates the formation of $\mathrm{BCC}$ bainitic microstructure in as-received material, but BCC martensitic microstructure in all the four deformed samples was analyzed in this work. Only $1130{ }^{\circ} \mathrm{C}-1 / \mathrm{s}$ sample shows the presence of negligible amount of FCC phase (in blue) along with BCC martensitic microstructure.

Figure 15 shows the effective grain size maps and respective inverse pole figure (IPF) maps for effective grains in the asreceived and the four deformed samples. The effective grain size maps show very fine and large grains in blue and red colors, respectively, and the scale bar below every map indicates the equivalent circle diameter of grains (in micron scale) present in that particular scan profile. The IPF maps, taken in the CD-RD plane, show the orientation of effective grains for each scan profiles. The as-received material mostly contains equiaxed effective grains with diameter range of 2$20 \mu \mathrm{m}$ and a few large grains in the range of $50-75 \mu \mathrm{m}$. A drastic decrease in the effective grains size is observed when the samples are deformed at $880{ }^{\circ} \mathrm{C}$. Irrespective of the strain rate, both $880{ }^{\circ} \mathrm{C}-0.001 / \mathrm{s}$ and $880{ }^{\circ} \mathrm{C}-1 / \mathrm{s}$ samples show similar equiaxed microstructure, where most of the effective grains are below $6 \mu \mathrm{m}$ with a few grains in the diameter range of 10 $16 \mu \mathrm{m}$. The IPF maps also show random grain orientation for the as-received material, which remains same following deformation at $880{ }^{\circ} \mathrm{C}$. A significant difference in both the effective grain size and shape results when the samples are deformed at $1130{ }^{\circ} \mathrm{C}$. Both $1130{ }^{\circ} \mathrm{C}-0.001 / \mathrm{s}$ and $1130{ }^{\circ} \mathrm{C}-1 / \mathrm{s}$ samples contain a significant amount of elongated effective grains (aspect ratio in the range of $3-18$ ). $1130{ }^{\circ} \mathrm{C}-0.001 / \mathrm{s}$ sample contains majority of the effective grains below $25 \mu \mathrm{m}$ diameter with a few grains in the range of 55-70 $\mu \mathrm{m}$. In case of the $1130{ }^{\circ} \mathrm{C}-1 / \mathrm{s}$ sample, almost all the effective grains are below $10 \mu \mathrm{m}$ along with very few grains within the 28-34 $\mu \mathrm{m}$ diameter range. The IPF maps show that the majority of the effective grains are oriented in between 001 and 111 directions for $1130{ }^{\circ} \mathrm{C}-0.001 / \mathrm{s}$ sample, and in between 101 and 111 directions for $1130{ }^{\circ} \mathrm{C}-1 / \mathrm{s}$ sample.

A summary of the average effective grain size (in terms of equivalent circle diameter) is shown in Fig. 16. The average effective grain size of the as-received sample $(\sim 10.5 \mu \mathrm{m})$ is decreased to almost $1 / 3^{\text {rd }}$ for the samples deformed at $880{ }^{\circ} \mathrm{C}$ $(\sim 3$ to $3.7 \mu \mathrm{m})$ and almost half for the samples deformed at $1130{ }^{\circ} \mathrm{C}(\sim 4$ to $6 \mu \mathrm{m})$. Irrespective of the deformation 


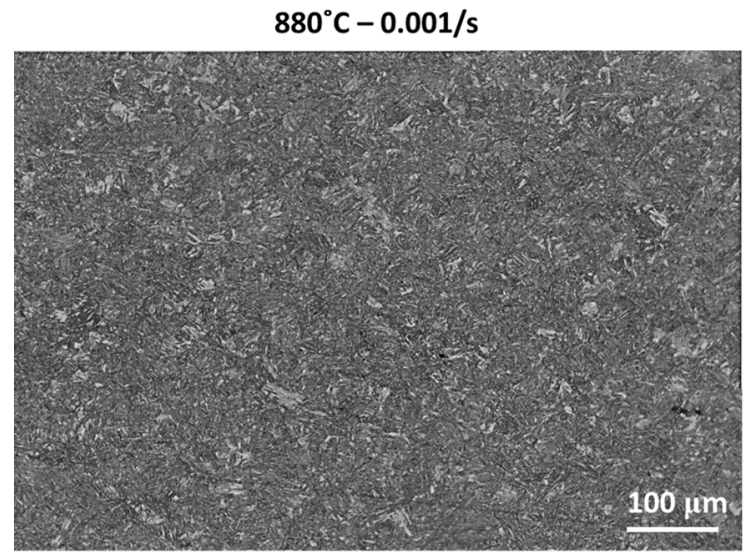

$1046^{\circ} \mathrm{C}-0.001 / \mathrm{s}$

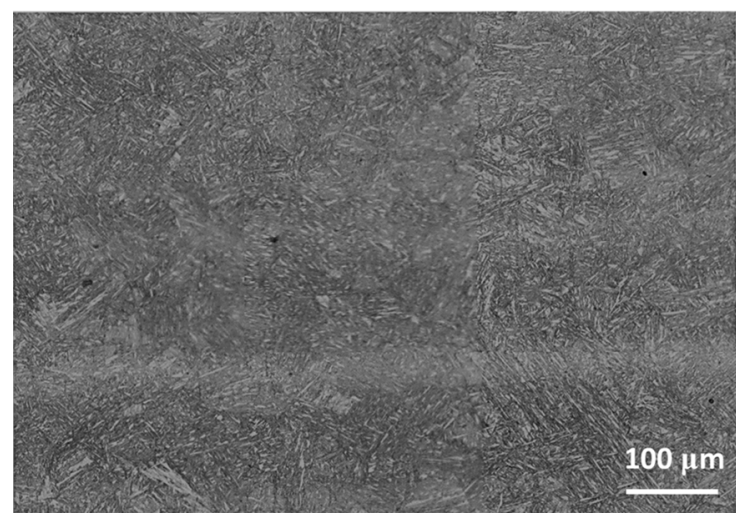

$963^{\circ} \mathrm{C}-0.001 / \mathrm{s}$

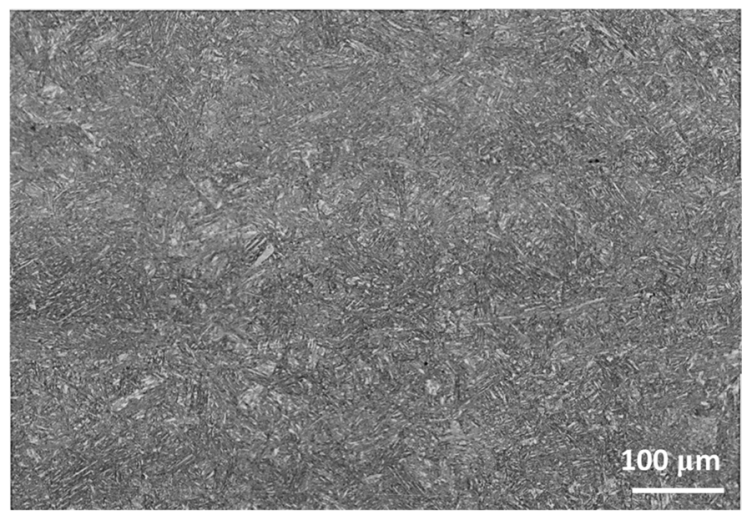

$1130^{\circ} \mathrm{C}-0.001 / \mathrm{s}$

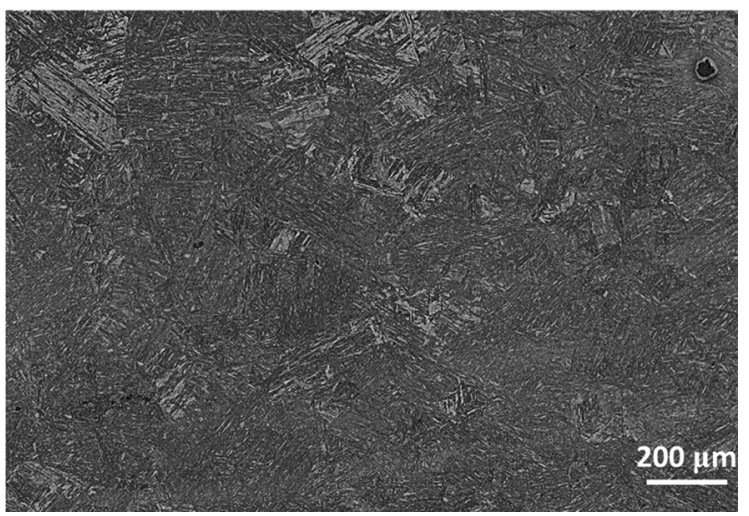

Fig. 12 Optical images showing the microstructure of samples deformed at true strain rate of $0.001 / \mathrm{s}$ and at different test temperatures (880$\left.1130{ }^{\circ} \mathrm{C}\right)$

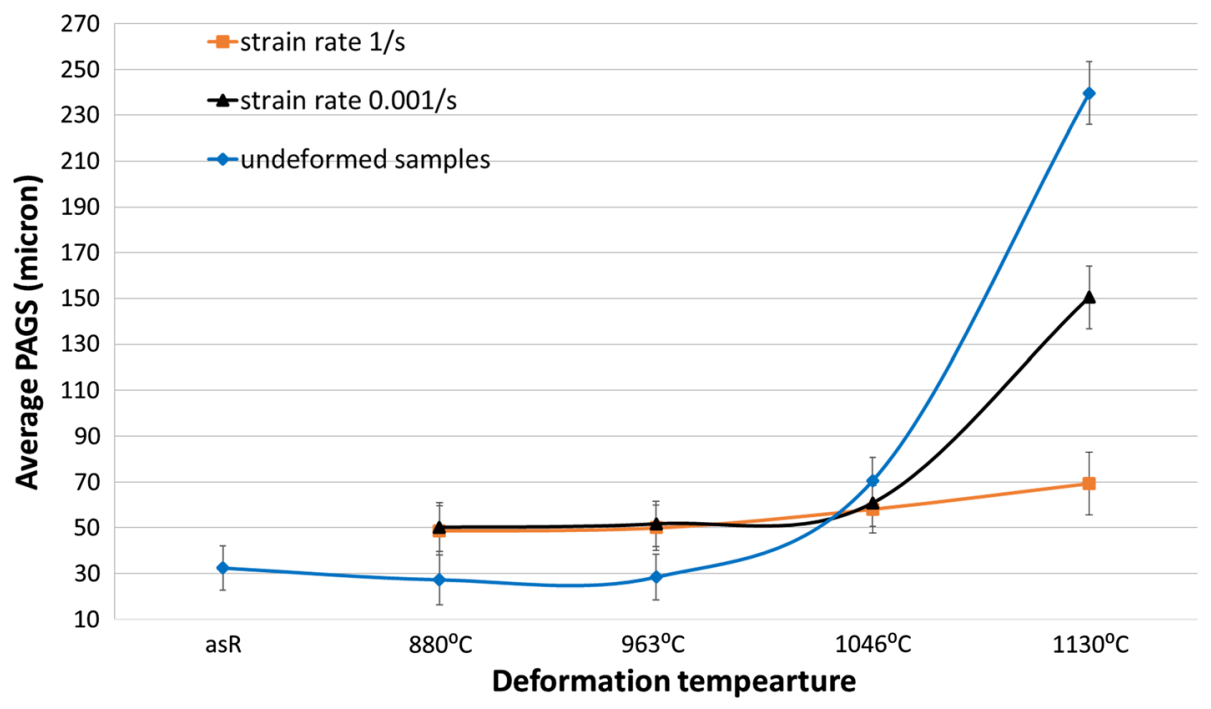

Fig. 13 Summary of PAGS analysis for as-received, undeformed and deformed SA508 grade 3 steel samples

temperature, the samples experiencing the highest strain rate of $1 / \mathrm{s}$ show more grain refinement as compared to those deformed at the lowest strain rate of $0.001 / \mathrm{s}$. Sun et al. (Ref 4) reported the occurrence of DRX in SA508 grade 3 steel in the temperature range of $800-900{ }^{\circ} \mathrm{C}$ and observed finer grains within that range. Dai and Yang (Ref 9) reported occurrence of DRX in SA508 grade 4 steel from $950{ }^{\circ} \mathrm{C}$ onwards and showed that lower strain rate deformation favored the growth behavior of DRX grains more. In this study, the finer effective grains observed at $880{ }^{\circ} \mathrm{C}$ indicate the occurrence of DRX and further grain refinement, particularly during $1 / \mathrm{s}$ test, is attributed to the occurrence of MDRX as evident from Fig. 15. A noticeable growth of these DRX grains is observed when the deformation temperature reached $1130{ }^{\circ} \mathrm{C}$. It is expected that the DRX 

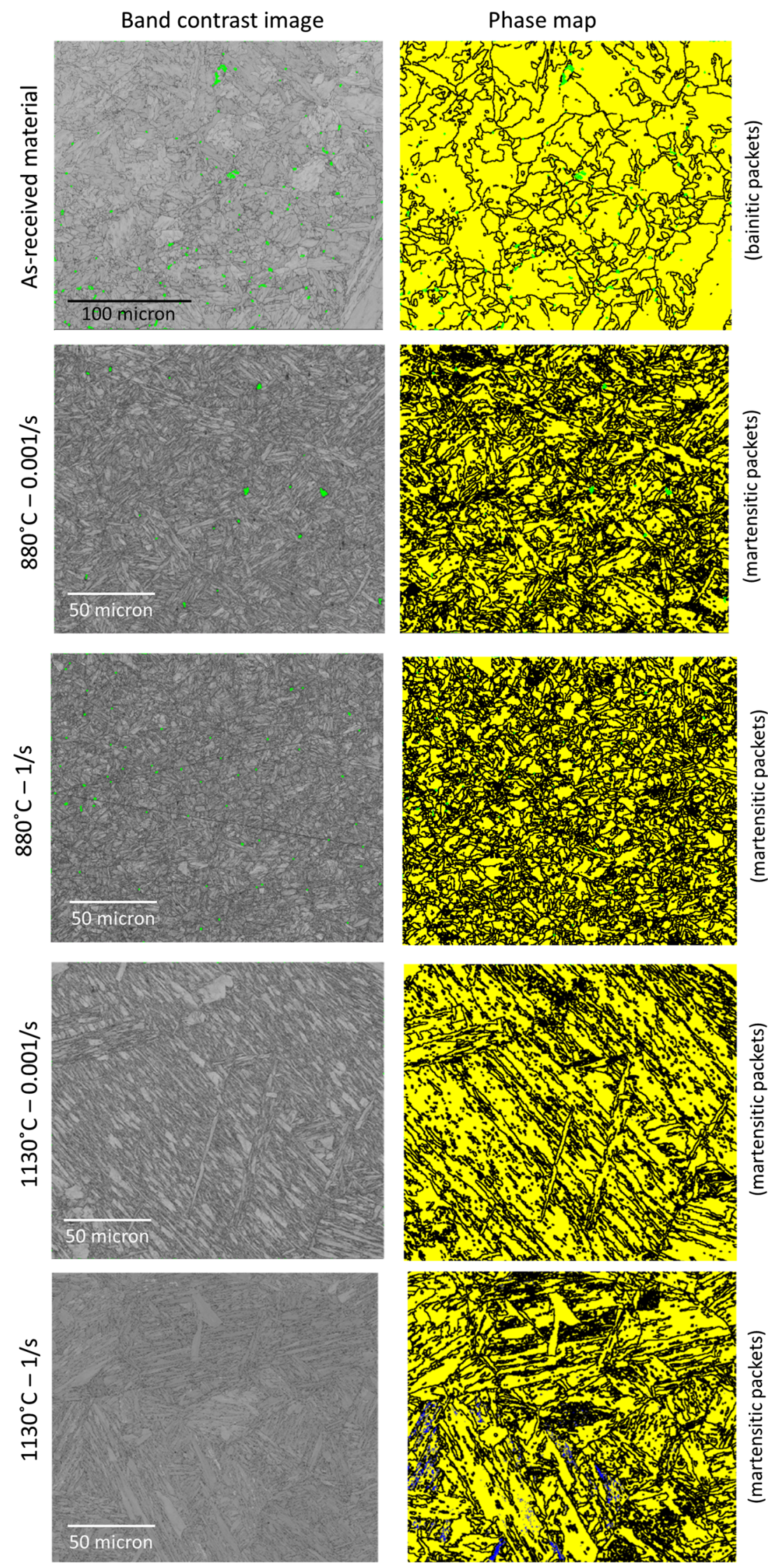

Fig. 14 Band contrast image (BC) and phase map (BCC in yellow and FCC in blue) showing microstructural evolution of the deformed SA508 grade 3 steel samples 

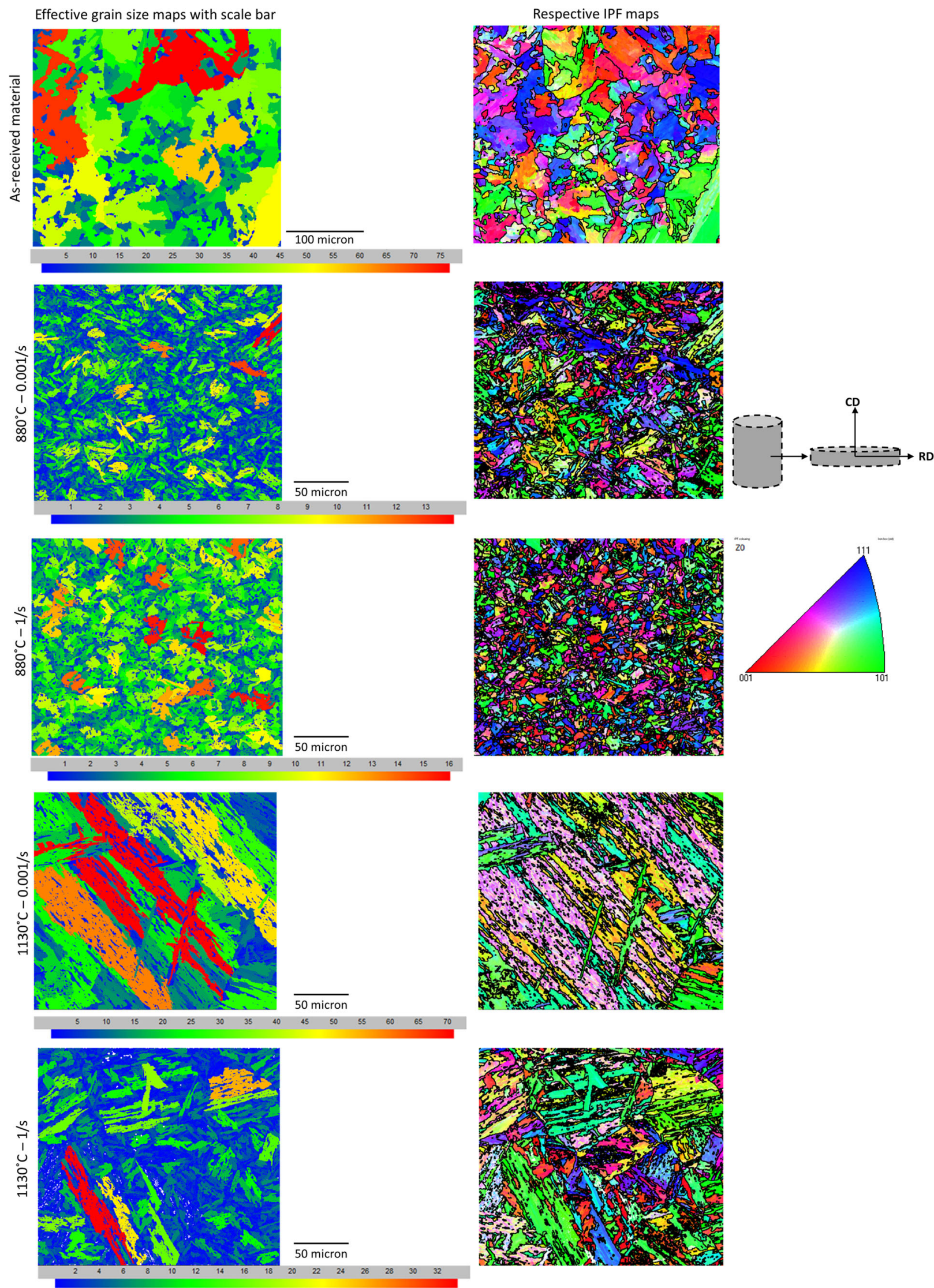

Fig. 15 Effective grain size maps and respective IPF maps as observed in as-received and deformed SA508 grade 3 steel samples 


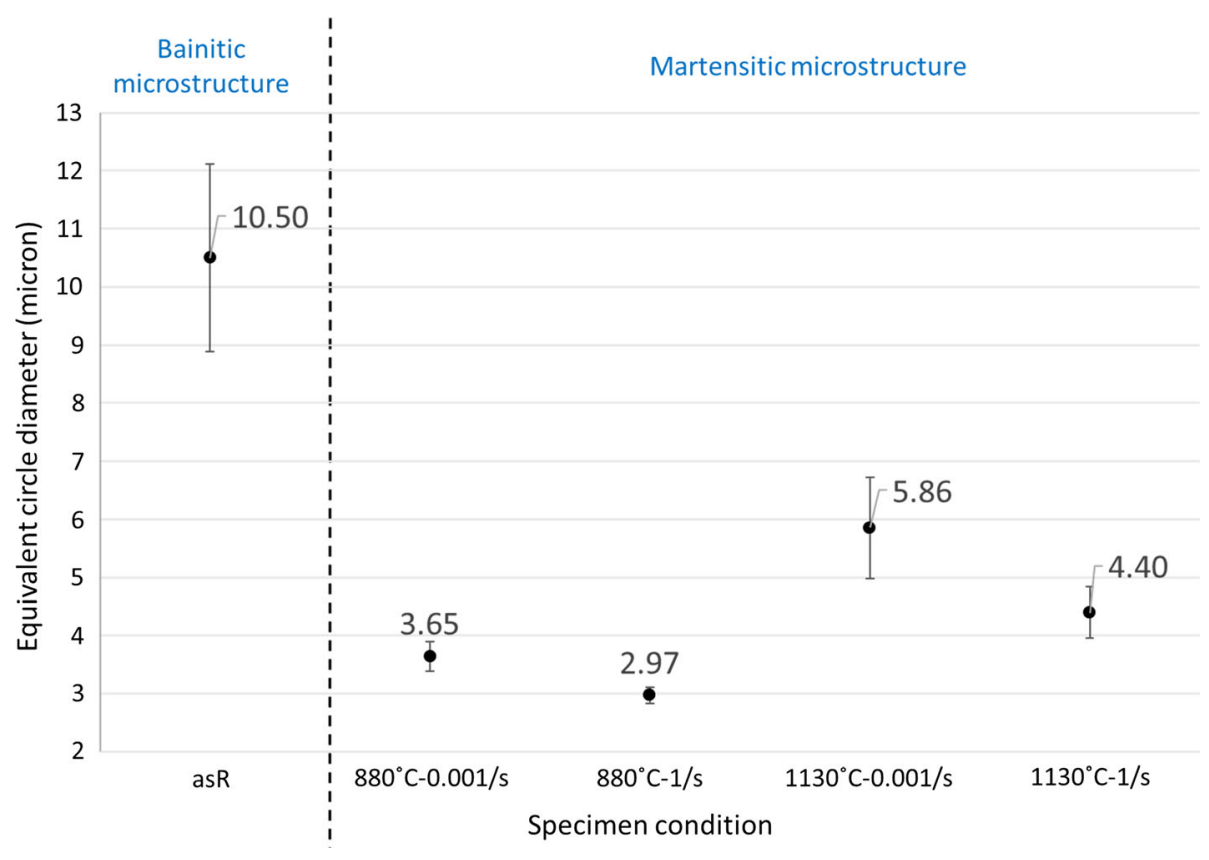

Fig. 16 Summary of the average effective grain size (in terms of equivalent circle diameter) as observed in as-received and deformed SA508 grade 3 steel samples

grains would experience some recovery (as evidence of DRV during deformation was clearly seen from the nature of the flow curves shown in Fig. 4) at that high temperature leading to grain growth particularly at a strain rate of $0.001 / \mathrm{s}$. However, it is difficult to quantify the DRX and the DRV separately due to austenitic to martensitic phase transformation during the water quenching stage after compression test.

\subsection{Texture Analysis}

The evolution of crystallographic texture from the asreceived to the various deformed conditions of SA508 grade 3 steel samples is presented in this section. Hu (Ref 29) showed that when uniaxial compression test was performed on BCC materials at room temperature, a preferred texture developed along a specific direction. During deformation, the active slip planes seem to have rotated toward the compression axis and as a result, the crystal orientation changed which led to development of compression texture. The compression texture was a mixture of 111 and 100 fibers, in which 111 was the major component. Figure 17 shows the pole figures of the as-received and deformed SA508 grade 3 steel samples for $\{111\},\{001\}$ and $\{101\}$ planes. In order to understand the effect of deformation temperature and strain rate on the texture strength, all the pole figures are plotted in the same scale, i.e., with a maximum density of 10 . The as-received material shows random fiber-type texture with a maximum density of 4.58 . As expected, the texture of the as-received material weakens when deformed at $880{ }^{\circ} \mathrm{C}$ and a decrease in texture strength is observed with increase in strain rate from 0.001 to $1 / \mathrm{s}$. Initially, a significantly strong peak-type texture with a maximum density of 22.14 was observed in $1130{ }^{\circ} \mathrm{C}-0.001 / \mathrm{s}$ sample. However, this was the case when the scanning was done within a small $175 \mu \mathrm{m} \times 150 \mu \mathrm{m}$ area. The strong texture was attributed to the same orientation of the acicular martensitic laths within this area. As observed in Fig. 13, the average PAGS of this samples is $\sim 151 \mu \mathrm{m}$; therefore, the small scanning area was likely to have covered almost same orientation of the acicular martensitic laths within a single large parent austenite grain (observed from the IPF map in Fig. 15). This led to a very strong peak-type texture, which was not representative of the forging operation at that condition, rather it mostly presented the texture of a random large parent austenite grain. In order to avoid this misrepresentation of texture, a large scanning area of $1 \mathrm{~mm} \times 1 \mathrm{~mm}$ is further chosen with $10 \mu \mathrm{m}$ step size for the EBSD scan. The obtained pole figure shows random fiber-type texture with a maximum density of 3.66, which is representative of forging operation at that condition. With an increase in strain rate to $1 / \mathrm{s}$, the density of the random fiber-type texture increases to 5.84. This random fiber-type weak deformation texture is expected from any forging operation, and it can be attributed to the exposure of a very high temperature leading to greater softening and coarsening of microstructure with higher degree of deformation. Hence, the EBSD analysis has been useful in quantifying the complex microstructure and texture, which is not possible by other means such as optical micrographs. The texture data, however, reveal no significant difference despite the changes of bainitic microstructure present in the as-received sample to the martensitic microstructure of the deformed samples.

\subsection{Hardness Analysis}

Figure 18 summarizes the average hardness of as-received and deformed steel samples. The hardness values of as-received material measured at different locations are averaged at $\sim 194$ HV. The samples deformed at $880{ }^{\circ} \mathrm{C}$ exhibit an average hardness of $\sim 427 \mathrm{HV}$ and $\sim 431 \mathrm{HV}$, in case of $0.001 / \mathrm{s}$ and $1 /$ $\mathrm{S}$ strain rates, respectively. The average hardness of $1130{ }^{\circ} \mathrm{C}$ $0.001 / \mathrm{s}$ and $1130{ }^{\circ} \mathrm{C}-1 / \mathrm{s}$ samples is $\sim 402 \mathrm{HV}$ and $\sim 425 \mathrm{HV}$, respectively, slightly lower than that observed at $880{ }^{\circ} \mathrm{C}$. It should be noted that the samples experiencing most work hardening and softening behavior, i.e., $880{ }^{\circ} \mathrm{C}-1 / \mathrm{s}$ and $1130{ }^{\circ} \mathrm{C}-0.001 / \mathrm{s}$, exhibit the highest and lowest average 

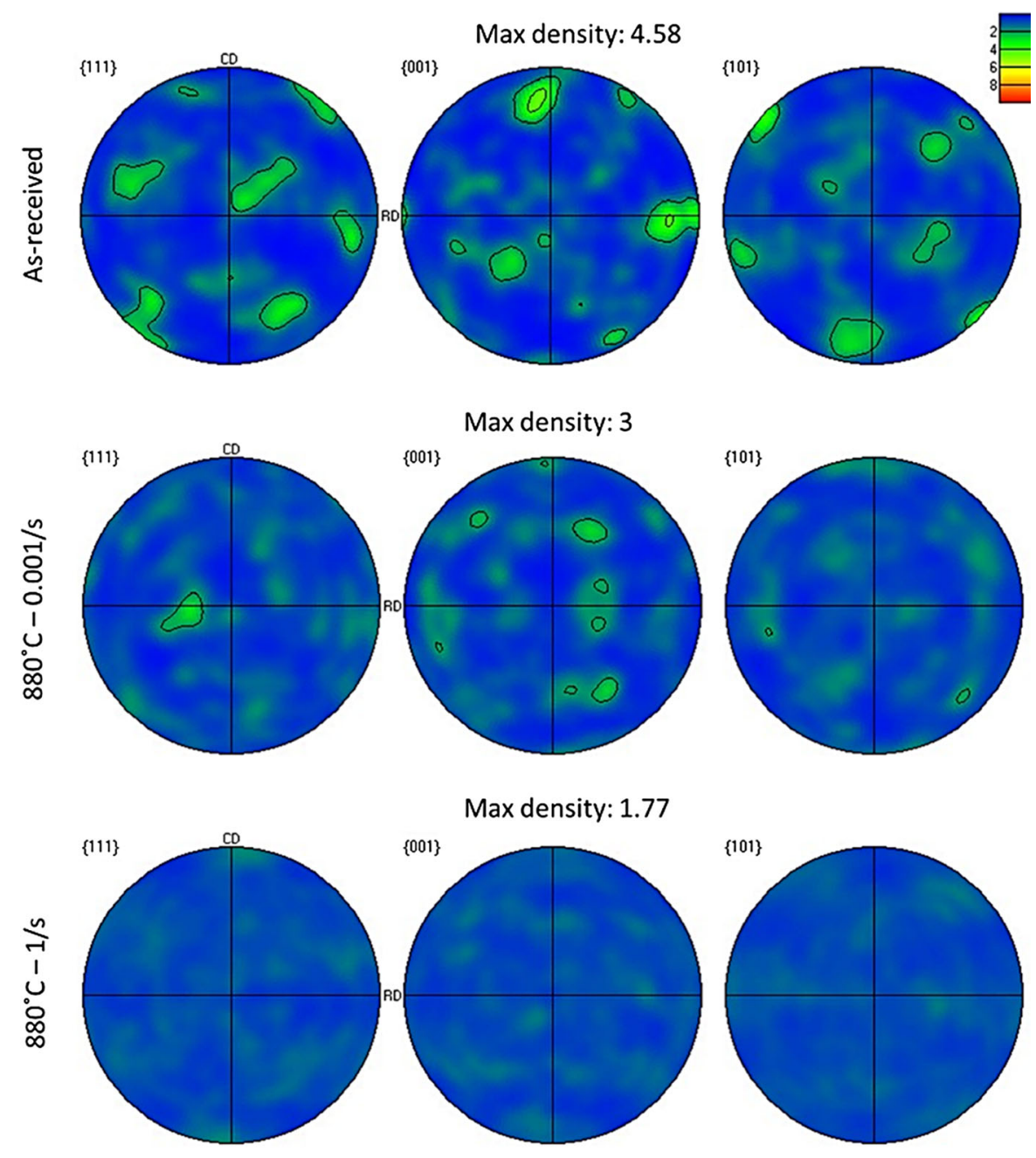

Max density: 3.66
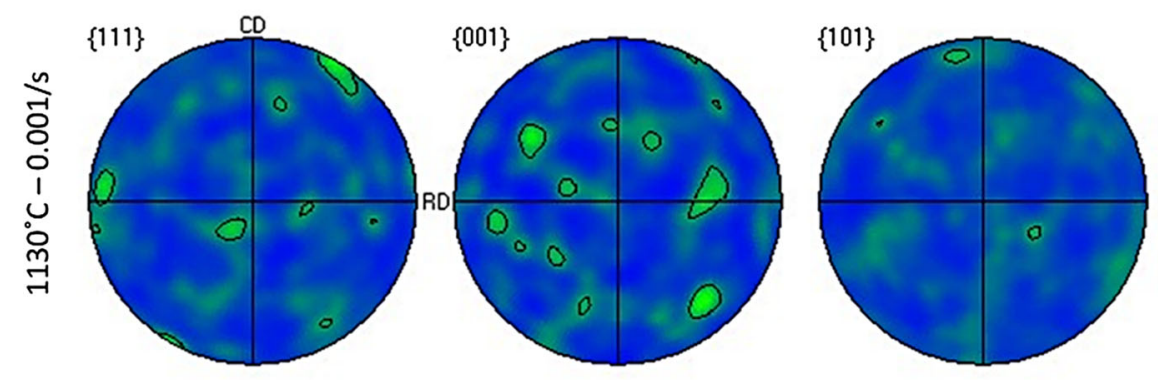

Max density: 5.84

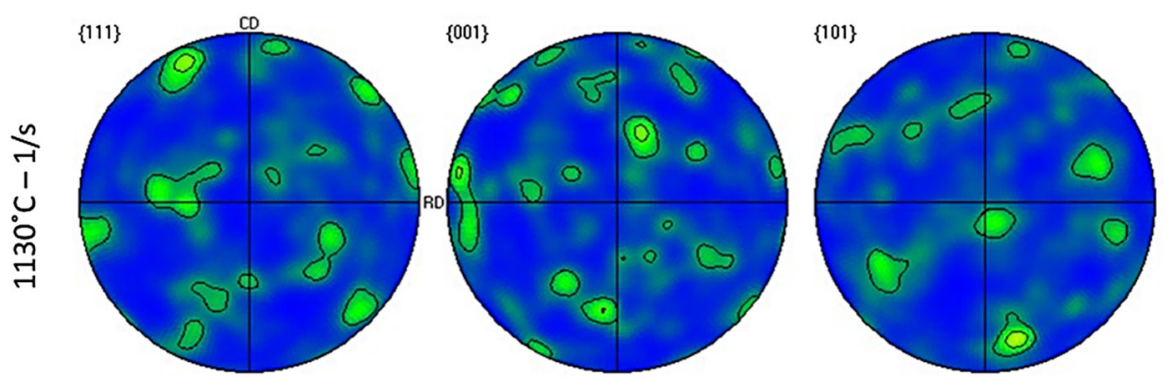

Fig. 17 Texture representation of as-received and deformed SA508 grade 3 steel samples 


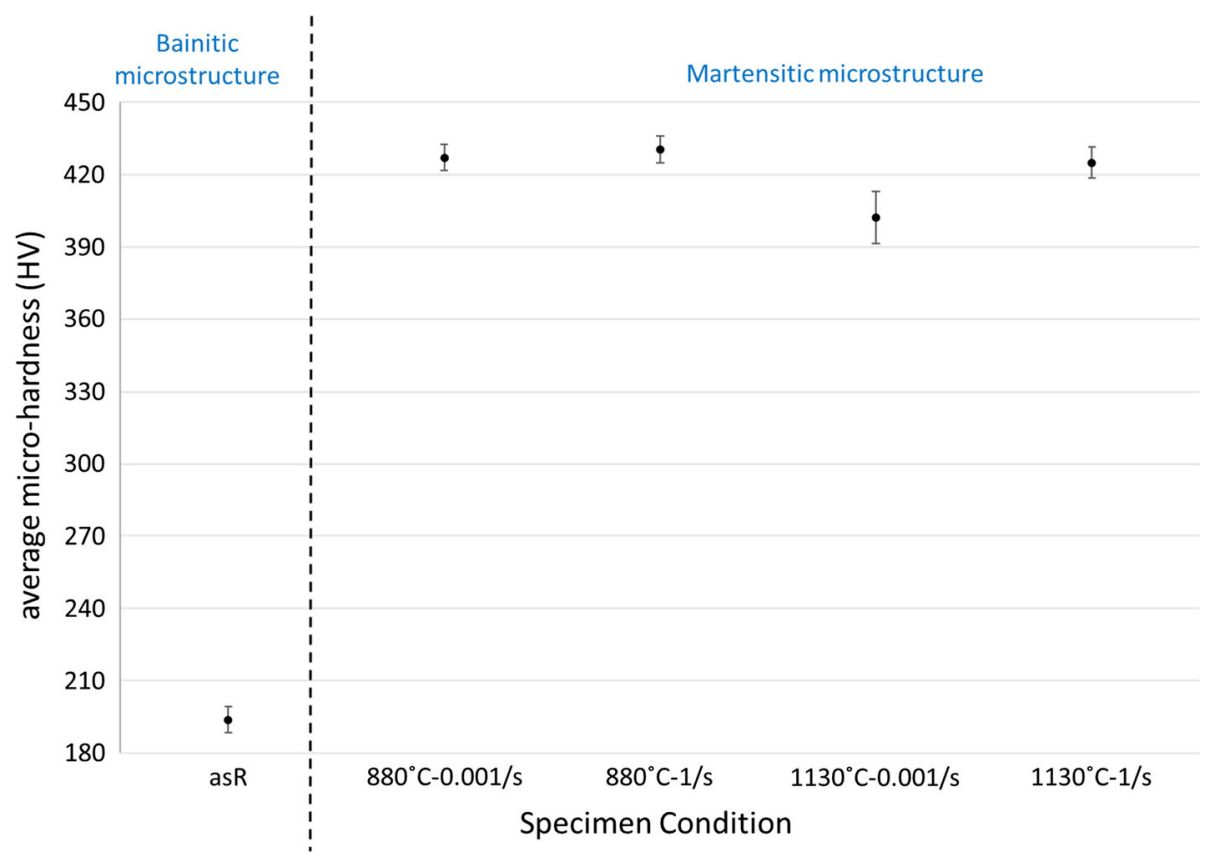

Fig. 18 Hardness summary of as-received and deformed SA508 grade 3 steel samples

hardness, respectively. The hardness characteristics can be directly linked with the respective microstructure and the average effective grain size. The as-received material contains bainitic microstructure with an average grain size of $\sim 10.5$ $\mu \mathrm{m}$, which exhibits the lowest average hardness value $(\sim 194$ HV) among all the samples. However, all the deformed samples show martensitic microstructure with substantially low average effective grain sizes $(\sim 3$ to $6 \mu \mathrm{m})$ resulting in significantly higher average hardness values ( $\sim 402$ to $431 \mathrm{HV})$ when compared to the as-received sample. Among the deformed samples, $880{ }^{\circ} \mathrm{C}-1 / \mathrm{s}$ and $1130{ }^{\circ} \mathrm{C}-0.001 / \mathrm{s}$ samples show the smallest and largest average effective grain sizes, i.e., $\sim 3 \mu \mathrm{m}$ and $\sim 6 \mu \mathrm{m}$, respectively, thus resulting in the highest and lowest average hardness values, respectively.

\section{Discussion}

Table 4 summarizes the key findings from the corrected flow stress behavior and the microstructural evolution of the SA508 grade 3 steel during hot deformation. The as-received material has bainitic microstructure with average effective grain size of $\sim 10.5 \mu \mathrm{m}$ and an average hardness of $\sim 194 \mathrm{HV}$. The combined effects of deformation temperature and true strain rate on this steel are apparent in case of two samples-(1) sample experiencing the highest work hardening, i.e., $880{ }^{\circ} \mathrm{C}$ $1 / \mathrm{s}$ and (2) sample showing most softening behavior, i.e., $1130{ }^{\circ} \mathrm{C}-0.001 / \mathrm{s}$. The corrected flow stress curves (Fig. 4) show the highest peak stress $(210.56 \mathrm{MPa})$ and a friction coefficient of 0.82 for $880{ }^{\circ} \mathrm{C}-1 / \mathrm{s}$ sample, whereas totally opposite behavior is observed for $1130{ }^{\circ} \mathrm{C}-0.001 / \mathrm{s}$ sample (peak stress of $19.7 \mathrm{MPa}$ and the lowest friction coefficient of 0.63). Both deformed samples exhibit similar austenitic to martensitic phase transformation during water quenching stage after hot deformation. The average PAGS for $880{ }^{\circ} \mathrm{C}-1 / \mathrm{s}$ and $1130{ }^{\circ} \mathrm{C}-0.001 / \mathrm{s}$ samples is observed as $\sim 49 \mu \mathrm{m}$ and $\sim 151$ $\mu \mathrm{m}$, respectively (Fig. 13). The high deformation temperature eventually reduces the Zener drag and eliminates the carbide particles from the initial microstructure, whereas low strain rate provides sufficient energy for such grain growth particularly in $1130{ }^{\circ} \mathrm{C}-0.001 / \mathrm{s}$ condition as already explained in Sect. 4.1. The martensitic microstructure of the deformed samples is quantified by calculating average effective grain size. The $880{ }^{\circ} \mathrm{C}-1 / \mathrm{s}$ sample exhibits equiaxed effective grains (i.e., finer laths) with random grain orientation, whereas the $1130{ }^{\circ} \mathrm{C}$ 0.001/s sample shows elongated effective grains (i.e., coarser laths) with a specific grain orientation between 001 and 111 directions (Fig. 15). MDRX appears to be the dominant deformation mechanism in $880{ }^{\circ} \mathrm{C}-1 / \mathrm{s}$ case, but no significant grain growth is noticed due to little deformation time before water quenching. As a result, finer laths are observed for $880{ }^{\circ} \mathrm{C}-1 / \mathrm{s}$ sample with an average effective grain size of $\sim 3 \mu \mathrm{m}$. On the other hand, the deformation time is more for the $1130{ }^{\circ} \mathrm{C}-0.001 / \mathrm{s}$ sample due to the combination of highest test temperature and lowest strain rate. In this case, the recrystallization occurs simultaneously with the deformation, which eventually leads to elongation of the already recrystallized grains, i.e., formation of coarser laths. The deformation is stopped due to water quenching before a subsequent cycle of recrystallization takes place; therefore, the average effective grain size remains highest (i.e., $\sim 6 \mu \mathrm{m}$ ) for $1130{ }^{\circ} \mathrm{C}-0.001 / \mathrm{s}$ sample when compared to others (Fig. 16). The DRV is normally dominant in BCC materials, but DRX can also occur under certain conditions, which is observed true in this study for samples deformed at $1130{ }^{\circ} \mathrm{C}$. This also implies that if the samples deformed at $1130{ }^{\circ} \mathrm{C}$ are furnace-cooled instead of water-quenched, then the effective grains would be initially equiaxed and finer due to having sufficient time for subsequent cycles of recrystallization. Then, these recrystallized grains would grow depending on the slow cooling rate of the furnace. In this study, the quantified microstructural data, i.e., average PAGS and average effective grain size calculated for different deformation conditions, can be directly correlated with the 


\begin{tabular}{|c|c|c|c|c|c|}
\hline \multirow[b]{2}{*}{ Properties of SA508 grade 3 steel } & \multirow[b]{2}{*}{$\begin{array}{l}\text { As-received } \\
\text { material }\end{array}$} & \multicolumn{4}{|c|}{ Deformed samples at following test conditions } \\
\hline & & $\begin{array}{l}880^{\circ} \mathrm{C}- \\
0.001 / \mathrm{s}\end{array}$ & $\begin{array}{l}880{ }^{\circ} \mathrm{C}- \\
1 / \mathrm{s}\end{array}$ & $1130{ }^{\circ} \mathrm{C}-0.001 / \mathrm{s}$ & $1130{ }^{\circ} \mathrm{C}-1 / \mathrm{s}$ \\
\hline Peak stress $(\mathrm{MPa})$ & NA & 84.67 & 210.56 & 19.7 & 69.38 \\
\hline Barreling coefficient & & 1.04 & 1.06 & 0.94 & 1.05 \\
\hline Tresca friction coefficient $(\mu)$ & & 0.81 & 0.82 & 0.63 & 0.71 \\
\hline Strain rate sensitivity $(\mathrm{m})$ & & \multicolumn{2}{|c|}{0.131 at $880^{\circ} \mathrm{C}$} & \multicolumn{2}{|c|}{0.182 at $1130^{\circ} \mathrm{C}$} \\
\hline $\begin{array}{l}\text { Mechanisms affecting the flow } \\
\text { behavior }\end{array}$ & & \multicolumn{2}{|c|}{ Work hardening } & \multicolumn{2}{|c|}{ Work hardening and thermally activated softening mechanisms } \\
\hline Microstructure & Bainitic & \multicolumn{2}{|l|}{ Martensitic } & & \\
\hline Average PAGS $(\mu \mathrm{m})$ & $\sim 32.36$ & $\sim 50.18$ & $\sim 48.69$ & $\sim 150.53$ & $\sim 69.16$ \\
\hline $\begin{array}{l}\text { Average effective grain, size } \\
\quad \text { (eq. circle dia., } \mu \mathrm{m})\end{array}$ & $\sim 10.5$ & $\sim 3.65$ & $\sim 2.97$ & $\sim 5.86$ & $\sim 4.4$ \\
\hline Aspect ratio of effective grains & $1.01-6.79$ & $1.02-10.98$ & $1.01-7.99$ & $1.09-18.04$ & $1.01-11.52$ \\
\hline Grain shape & Equiaxed & & & Elongated & \\
\hline Phases present & $\mathrm{BCC}$ & \multicolumn{2}{|l|}{$\mathrm{BCC}$} & \multicolumn{2}{|r|}{$\mathrm{BCC}+\mathrm{FCC}$} \\
\hline Grain orientation & Random & & & Between 001 and 111 directions & Between 101 and 111 directions \\
\hline Deformation texture & \multicolumn{3}{|c|}{ Random fiber-type } & & \\
\hline $\begin{array}{l}\text { Max strength }(m u d) \text { of the pole fig- } \\
\text { ure }\end{array}$ & 4.58 & 3 & 1.77 & 3.66 & 5.84 \\
\hline Average hardness (HV) & $193 \pm 5$ & $427 \pm 5$ & $431 \pm 5$ & $402 \pm 11$ & $425 \pm 6$ \\
\hline
\end{tabular}

average hardness of the respective samples according to HallPetch relationship. For example, $880{ }^{\circ} \mathrm{C}-1 / \mathrm{s}$ and $1130{ }^{\circ} \mathrm{C}$ $0.001 / \mathrm{s}$ samples have smallest and largest average effective grain sizes $(\sim 3 \mu \mathrm{m}$ and $\sim 6 \mu \mathrm{m}$, respectively); thus, they exhibit highest and lowest average hardness values $(\sim 431 \mathrm{HV}$ and $\sim 402 \mathrm{HV}$, respectively, Fig. 18). Beside this, another important factor is the strain rate sensitivity $(m)$, which is observed as 0.131 and 0.182 at $880{ }^{\circ} \mathrm{C}$ and $1130{ }^{\circ} \mathrm{C}$, respectively, indicating the stability of the hot forging operation performed within this temperature range (Fig. 7). This is further supported by the texture analysis, where a random fiber-type weak deformation texture is appeared in all deformed samples indicating the stability of the hot forging operation within the specified parametric range (Fig. 17). The significance of these findings is the quantification of the key mechanical and microstructure data for the test conditions that closely represent the industrial open die forging of SA508 grade 3 steel. The data produced in this work provide insight into the softening mechanisms occurring in this steel during hot forging. The quantified average PAGS and average effective grain size, the corrected flow stress behavior and the hardness data altogether provide vital inputs to the FE process models making the prediction of mechanical and microstructure properties in the end products more accurate. Thus, the effective forging conditions should always be identified based on the requirement of microstructural and mechanical properties for the end application.

\section{Conclusions}

Following conclusions are drawn from the current work:

- Highest work hardening in SA508 grade 3 steel is ob- served at the lowest test temperature and at the highest strain rate condition, i.e., $880{ }^{\circ} \mathrm{C}-1 / \mathrm{s}$, exhibiting highest peak stress. MDRX is the dominant deformation mechanism for this sample resulting in significant grain refinement (finer laths having average effective grain size of $\sim 3 \mu \mathrm{m})$ and therefore highest average hardness $(\sim 431 \mathrm{HV})$ as compared to rest of the conditions. In this case, no stable iron oxide film at the interface between the sample and the platens is formed, which leads to highest interfacial friction coefficient $(0.82)$ during hot deformation.

- Flow softening is observed dominant at the highest test temperature and at the lowest strain rate condition, i.e., $1130{ }^{\circ} \mathrm{C}-0.001 / \mathrm{s}$, showing lowest peak stress. DRV is found as dominant deformation mechanism as opposed to DRX. In this case, the recrystallization occurs simultaneously with the deformation due to prolonged deformation time. As a result, the recrystallized grains are elongated during deformation leading to coarser laths with an average effective grain size of $\sim 6 \mu \mathrm{m}$. The highest average effective grain size leads to lowest average hardness $(\sim 402 \mathrm{HV})$ as compared to others maintaining HallPetch relationship. Beside this, the prolonged deformation time is beneficial in order to form a stable iron oxide film at the interface between the sample and the platens. This lubricious oxide scale leads to a substantial decrease in the friction coefficient $(0.63)$ as compared to rest of the conditions.

- Within the temperature range of $880-1130{ }^{\circ} \mathrm{C}$, the strain rate sensitivity $(m)$ is observed in between 0.131 and 0.182 indicating stability of the hot forging process within the specified parametric range.

- The hardness of deformed samples is ranged from $\sim 402$ to $\sim 431 \mathrm{HV}$, which is more than twice the amount of hardness exhibited by the as-received material of $\sim 194$ 
HV. Despite the high-temperature deformation and the softening processes, it is the characteristic transformation from bainitic to martensitic microstructure, resulting from water quenching at the end of the hot deformation that leads to this significant hardness increase.

\section{Open Access}

This article is licensed under a Creative Commons Attribution 4.0 International License, which permits use, sharing, adaptation, distribution and reproduction in any medium or format, as long as you give appropriate credit to the original author(s) and the source, provide a link to the Creative Commons licence, and indicate if changes were made. The images or other third party material in this article are included in the article's Creative Commons licence, unless indicated otherwise in a credit line to the material. If material is not included in the article's Creative Commons licence and your intended use is not permitted by statutory regulation or exceeds the permitted use, you will need to obtain permission directly from the copyright holder. To view a copy of this licence, visit http://creativecommons.org/licenses/by/4.0/.

\section{Data Availability}

The raw/processed data required to reproduce these findings cannot be shared at this time due to legal or ethical reasons. Currently, the authors do not have permission to share this data.

\section{References}

1. P. Bowen, S.G. Druce, and J.F. Knott, Effects of Microstructure on Cleavage Fracture in Pressure Vessel Steel, Acta Metall., 1986, 34(6), p 1121-1131 (in English)

2. Y.R. Im, Y.J. Oh, B.J. Lee, J.H. Hong, and H.C. Lee, Effects of Carbide Precipitation on the Strength and Charpy Impact Properties of Low Carbon Mn-Ni-Mo Bainitic Steels, J. Nucl. Mater, 2001, 297(2), p 138-148 (in English)

3. H. Pous-Romero, I. Lonardelli, D. Cogswell, and H.K.D.H. Bhadeshia, Austenite Grain Growth in a Nuclear Pressure Vessel Steel, Mater. Sci. Eng. A, 2013, 567, p 72-79 (in English)

4. M. Sun, L. Hao, S. Li, D. Li, and Y. Li, Modelling Flow Stress Constitutive Behaviour of SA508-3 Steel for Nuclear Reactor Pressure Vessels, J. Nucl. Mater, 2011, 418, p 268-280 (in English)

5. D.S. Sui, F. Chen, P.P. Zhang, and Z.S. Cui, Numerical Simulation of Microstructure Evolution for SA508-3 Steel during Inhomogeneous Hot Deformation Process, J. Iron. Steel Res. Int., 2014, 21(11), p 10221029 (in English)

6. D. Dong, F. Chen, and Z.S. Cui, Investigation on Metadynamic Recrystallization Behaviour in SA508-III, Steel During Hot Deformation, J. Manuf. Process., 2017, 29, p 18-28 (in English)

7. K. Osakada, Effects of Strain Rate and Temperature in Forming Processes of Metals, Journal de Physique IV Colloque, 1997, 07(C3), p C3-37-C3-47 (in English)

8. K. Natesan, S. Majumdar, P. S. Shankar and V. N. Shah, Preliminary Materials Selection Issues for the Next Generation Nuclear Plant
Reactor Pressure Vessel, U.S. Department of Energy, September 2006 (in English)

9. X. Dai and B. Yang, Hot Deformation Behavior and Microstructural Evolution of SA508-IV Steel, Steel Res. Int., 2019, 20(5), p 1800208 ((in English))

10. B. Roebuck, J.D. Lord, M. Brooks, M.S. Loveday, C.M. Sellars, and R.W. Evans, Measuring Flow Stress in Hot Axisymmetric Compression Tests, Mater. High Temp., 2006, 23(2), p 59-83 (in English)

11. A. International, "Standard Test Methods for Determining Average Grain Size (Designation: E112 - 13) (2016) (in English)

12. R. Evans and P. Scharning, Strain Inhomogeneity in Hot Axisymmetric Compression Test, Mater. Sci. Technol., 2002, 18(11), p 1389-1398 (in English)

13. F.J. Humphreys, Characterisation of Fine-Scale Microstructure by EBSD, Scr. Mater., 2004, 51(8), p 771-776 (in English)

14. ASTM International (2015) Standard Test Method for Knoop and Vickers Hardness of Materials (Designation: E384-11) (in English)

15. Vickers Hardness Testing, www.struers.com. https://www.struers.com/ en-GB/Knowledge/Hardness-testing/Vickers\# (in English)

16. G.E. Dieter, Mechanical Metallurgy, McGraw Hill, New York, 1981

17. Z. Wan, L. Hu, Y. Sun, T. Wang, and Z. Li, Hot Deformation Behavior and Processing Workability of a Ni-Based Alloy, J. Alloys Compd., 2018, 769, p 367-375 (in English)

18. J. Zhang, H. Di, H. Wang, K. Mao, T. Ma, and Y. Cao, Hot Deformation Behavior of Ti-15-3 Titanium Alloy: A Study Using Processing Maps, Activation Energy Map, and Zener-Hollomon Parameter Map, J. Mater. Sci., 2012, 47(9), p 4000-4011 (in English)

19. S. Davenport, N. Silk, C. Sparks, and C. Sellars, Development of Constitutive Equations for Modelling of Hot rolling, Mater. Sci. Technol., 2000, 16(5), p 539-546 (in English)

20. H. Feng, Z. Jiang, H. Li, W. Jiao, X. Li, H. Zhu, S. Zhang, B. Zhang, and M. Cai, Hot Deformation Behavior and Microstructural Evolution of High Nitrogen Martensitic Stainless Steel 30Cr15Mo1N, Steel Res. Int., 2017, 88, p 1700149 (in English)

21. Y. Li, E. Onodera, and A. Chiba, Friction Coefficient in Hot Compression of Cylindrical Sample, Mater. Trans., 2010, 51(7), p 1210-1215 (in English)

22. V. Panjkovic, Chapter 11-Tribological Properties of Oxidised Metals and Carbides, In: Friction and the Hot Rolling of Steel, CRC Press, Boca Raton, 2014, p 95-105 (in English)

23. S. Papaefthymiou, M. Bouzouni, and R.H. Petrov, Study of Carbide Dissolution and Austenite Formation During Ultra-Fast Heating in Medium Carbon Chromium Molybdenum Steel, Metals, 2018, 8(8), p 646 (in English)

24. S. Morito, H. Tanaka, R. Konishi, T. Furuhara, and T. Maki, The Morphology and Crystallography of Lath Martensite in Fe-C Alloys, Acta Mater., 2003, 51, p 1789-1799 (in English)

25. S. Morito, Y. Adachi, and T. Ohba, Morphology and Crystallography of Sub-Blocks in Ultra-Low Carbon Lath Martensitic Steel, Mater. Trans., 2009, 50(8), p 1919-1923 (in English)

26. S. Morito, A. Pham, T. Hayashi, and T. Ohba, Block boundary analyses to identify martensite and bainite, Mater. Today Proc., 2015, 2, p S913S916 (in English)

27. O. Sherby, J. Wadsworth, D. Lesuer, and C. Syn, The c/a Ratio in Quenched Fe-C and Fe-N steels-a Heuristic Story, In: THERMEC 2006, Vancouver, Canada, 2006 (in English)

28. A. Brust, S. Niezgoda, V. Yardley, and E. Payton, Analysis of Misorientation Relationships Between Austenite Parents and Twins. April 2018. https://Arxiv.Org/Pdf/1804.02506.Pdf (in English)

29. H. Hu, Texture of Metals, Texture, 1974, 1, p 233-258 (in English)

Publisher's Note Springer Nature remains neutral with regard to jurisdictional claims in published maps and institutional affiliations. 